$$
L A-S U B-95-141
$$

\title{
ASSESSMENT OF REMOTE SENSING TECHNOLOGIES \\ TO DISCOVER AND CHARACTERIZE \\ WASTE SITES
}

\author{
Prepared by
}

Environmental Research Institute of Michigan

11 March 1992

\section{Final Report 242900-8-T on Subcontract 9-XC2-Y9152-1 with Los Alamos National Laboratory}

\author{
Attention: Edward Van Eeckhout, Allan Connor, Hugh Murphy, Dora Vigil
}

\section{DISCLAIMER}

\begin{abstract}
This report was prepared as an account of work sponsored by an agency of the United States Government. Neither the United States Government nor any agency thereof, nor any of their employees, makes any warranty, express or implied, or assumes any legal liability or responsibility for the accuracy, completeness, or usefulness of any information, apparatus, product, or process disclosed, or represents that its use would not infringe privately owned rights. Reference herein to any specific commercial product, process, or service by trade name, trademark, manufacturer, or otherwise does not necessarily constitute or imply its endorsement, recommendation, or favoring by the United States Government or any agency thereof. The views and opinions of authors expressed herein do not necessarily state or reflect those of the United States Government or any agency thereof.
\end{abstract}




\section{DISCLAMMER}

Portions of this document may be illegible in electronic image products. Images are produced from the best available original document. 


\section{ASSESSMENT OF REMOTE SENSING TECHNOLOGIES}

TO DISCOVER AND CHARACTERIZE

WASTE SITES

Table of Contents

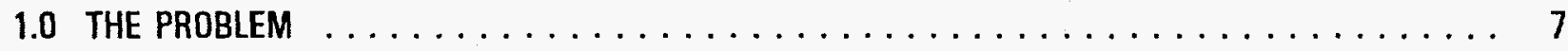

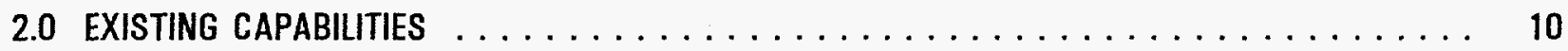

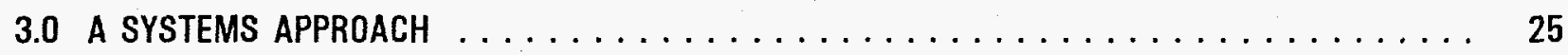

4.0 SPECIAL SENSOR TECHNOLOGYIPROCESSING $\ldots \ldots \ldots \ldots \ldots \ldots \ldots \ldots \ldots$

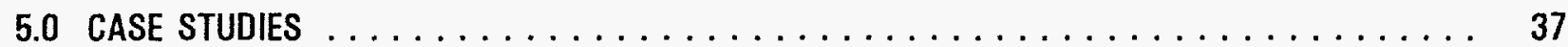

6.0 SUMMARY OF RECOMMENDATIONS $\ldots \ldots \ldots \ldots \ldots \ldots \ldots \ldots \ldots \ldots$

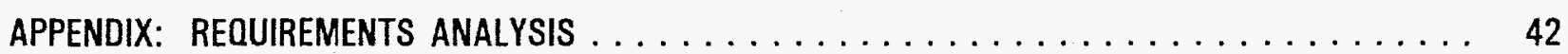


List of Tables

2.1 Multispectral Images from Landsat and SPOT as of March 1992

$2.2 \quad$ Spectral Regions

2.3 Landsat Thematic Mapper Bands

2.4 Comparison of Landsat Multispectral Scanner, Thematic Mapper, and SPOT

2.5 Example Catalogue of Spectral Imaging Satellite Systems in the World

2.6 Example Catalogue of Radar Imaging Satellite Systems in the World

2.7 Example Catalogue of Radar Imaging Aircraft Systems in the World

2.8 Example Catalog of Film Camera Imaging Satellite or Aircraft Systems in the World

3.1 Example of Matching Target Observables to Signature Observables to Sensors

3.2 Definitions of Sensor Codes listed in the far right column of Table 3.1

4.1 Example of Method for Comparing Sensor Alternatives

A.1 Definitions of Sensor Codes listed in the far right column of Tables A.9.x.x.

A.2 DOE Problem Description

A.3 DOE Problem Set vs. Problem Element

A.4 Problem Elements vs. Information Elements

A.5 Information Elements vs. Target Observables

A.6.1-2 Example of One Problem Element Derived from DOE Problem Sets

A.7 Example of Information Elements for One Problem Element Derived from DOE Problem Sets 
List of Tables (cont.)

A.8.1-2 Example of Target Observables and Signature Observables for One Information Element Associated with One Problem Element Derived from DOE Problem Sets

A.9.1.1-3 Target Observables, Signature Observables, and potential Sensors Associated with Information Elements Derived from "Site Location" Problem Element

A.9.2.1-3 Target Observables, Signature Observables, and potential Sensors Associated with Information Elements Derived from "Soils-Basin/Ponds Containing Low Level Waste (LLW) and Hazardous Wastes" Problem Element

A.9.3.1-3 Target Observables, Signature Observables, and potential Sensors Associated with Information Elements Derived from "Contaminated Soils-Mixed Waste" Problem Element

A.9.4.1-6 Target Observables, Signature Observables, and potential Sensors Associated with Information Elements Derived from "Burial Grounds Containing Radioactive and Hazardous Wastes" Problem Element

A.9.5.1-3 Target Observables, Signature Observables, and potential Sensors Associated with Information Elements Derived from "Sludges in Tanks" Problem Element

A.9.6.1-2 Target Observables, Signature Observables, and potential Sensors Associated with Information Elements Derived from "Ground Water Contaminated with Radionuclides, Organics, and Inorganics" Problem Element

A.9.7.1-9 Target Observables, Signature Observables, and potential Sensors Associated with Information Elements Derived from "Subsurface Contaminants" Problem Element 
List of Figures

$3.1 \quad$ Interplay of Studies 


\section{ASSESSMENT OF REMOTE SENSING TECHNOLOGIES \\ TO DISCOVER AND CHARACTERIZE \\ WASTE SITES}

\section{EXECUTIVE SUMMARY}

Identification and characterization of waste sites at DOE facilities presents severe challenges. Optical and radio wave remote sensing technologies, especially as implemented from aircraft and satellites, provide an important, highly cost-effective complement to on-site, invasive, and other intensive approaches. Extensive development of these technologies for defense and civilian applications has occurred over the last several decades. There is now a broad array of satellite and aircraft sensors available to the civilian community. While it is clear that no single remote sensing approach will, or even all approaches in concert, will solve all site characterization problems, it is equally clear that remote sensing approaches will be valuable. Work is needed to identify the phenomenologies and sensors and to develop the methodologies best suited to location and characterization of DOE (or other) waste sites either by remote sensing alone or by remote sensing in concert with other approaches.

This report provides:

- An overview of available and anticipated sensor systems and currently existing data over a number of DOE sites.

- A summary of promising phenomenologies and sensors to address waste site location and characterization problems.

- An initial plan for selecting and evaluating remote sensing approaches and sensors for application to the DOE waste site problem. 


\subsection{THE PROBLEM}

The Department of Energy (DOE) has initiated an effort to remediate waste sites at all of its facilities in a campaign of environmental restoration. The effort includes all available means to identify, reclaim, and restore these lands to as close to their original state as can be expected. Once the sites and problems have been located and characterized, and an achievable restoration/remediation program has been established, efforts to reclaim the environment will begin.

The sequence of activities anticipated for DOE waste site restoration are listed in the DOE 1989 Applied Research, Development, Demonstration, Testing and Evaluation (RDDT\&E) draft plan as:

- strategic planning,

- characterization,

- assessment,

- remediation, and

- compliance monitoring.

This report concerns the Characterization phase.

Individual DOE waste sites vary from plant discharge outfall sites, which can be as small as 10 square meters, to landfills ranging in size from 1,000 to 10,000 square meters. DOE waste sites are distributed throughout the U.S., where climatic and vegetative conditions vary from humid and sub-tropical, as at the Savannah River Site in South Carolina, to arid, as at the Hanford site in Washington State. Soils range from silt and clay, as at the Fernald site in Ohio, to alluvial fill at Sandia National Laboratory in Albuquerque, to basaltic sheet flows at Hanford. Depths of ground water vary from zero to well over 600 meters. Wastes include organics such as solvents and lubricating oils, heavy metals such as chromium, mercury, and lead, and radioactive materials, including uranium and transuranic materials. Special problems to be considered in characterization include:

- concentrated waste forms such as in buried tanks and pits,

- soil and groundwater contamination,

- ground safety hazards for workers,

- intrusive nature of some current methods,

- high cost of drilling holes, and

- requirement for long-term monitoring. 
Recognizing that many of these problems cannot be solved in conventional ways, the DOE has called for special innovative technologies in the RDDT\&E plan. Transferring technology from $\mathrm{DOD}$ and other applications, upgrading existing sensors/methods, and developing new technology are all appropriate; technology that is now available should be demonstrated to determine its utility.

The Los Alamos National Laboratory has been asked by DOE's Office of Technology Development to assess the capabilities of current technology to locate and characterize waste sites and to then make recommendations. A workshop was hosted by Los Alamos in Dallas, Texas, on August 29-30, to review current technology and then make recommendations for use of noninvasive ground-based geophysical technology to characterize waste sites. Technologies were presented and ranked in terms of the development needed. The technology development areas that were expected to have the most benefit to DOE for the least cost are (with highest benefit to cost ratio first):

- data fusion,

- electromagnetic methods,

- ground penetrating radar,

- seismic methods,

- gravity methods, and

- magnetic methods.

Remote sensing methods can be utilized in a comprehensive approach with historical and ancillary data, traditional ground-based methods, and a plan for coordinated coverage. Remote sensing methods are especially attractive in that they involve no safety hazards to workers on the ground and do not destroy evidence nor damage the environment any further. They can be cost-effective because some currently available methods are readily applied and relatively inexpensive to the user.

The Environmental Research Institute of Michigan (ERIM) has been asked by Los Alamos to prepare this report as input to the Los Alamos effort. It provides suggestions for non-invasive methods to discover and characterize waste sites, focusing on optical and radio-wave remote sensing technologies, especially those which can be applied from aircraft and satellites. ${ }^{\prime}$ It is a preliminary assessment of current and proposed non-invasive

1 Remote sensing is sometimes considered to include seismic and nuclear approaches. These were considered in the Dallas workshop, but are only mentioned here. 
technology that was not fully covered at the Dallas workshop. Recommendations are summarized at the end of this report.

$\bullet$

?

0

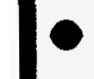

-

0 


\subsection{EXISTING CAPABILITIES}

The report starts with a partial catalogue of existing data sources, descriptions of relevant current systems, and a selected bibliography on remote sensing.

\subsection{Catalogue of Existing Data Sources}

Data archives/bases exist for a number of satellite imagery sources. Data on broad-area coverage by low resolution systems such as AVHRR is generally available and imagery will be especially useful with maps in a Geographic Information System (GIS)-type of system. It is highly likely that mid-level resolution satellite systems such as Landsat and SPOT will be important contributors to detecting waste sites and monitoring them for indicators of change. Data bases for these are quite easy to access and are discussed below.

A number of airborne systems offer better resolution than is available from the majority of satellite systems and some archives exist back to the 1940s. However, these data are harder to locate and access than that from satellite systems. Users need to rely heavily on personal knowledge and contacts and word-of-mouth as most information from airborne systems has not been well-documented. Some specific sources are discussed below.

\subsubsection{Multispectral Data}

A data search was made for this project covering the period 1972-1992. The search provided data that exemplifies the kind of information available. Data bases for three types of systems were searched, the Landsat TM (Thematic Mapper) and Multispectral Scanner (MSS) databases maintained by EOSAT, the SPOT Image Customer Service database, and ERIM's own database of multispectral aircraft collections.

ERIM is a frequent user of Landsat and SPOT so it has on-line access to these data base systems; however, these sensor data are also commercially available to anyone via customer service representatives: for Landsat contact EOSAT Customer Services Department $800 / 344-9333$ or $301 / 522-0537$ and for SPOT contact SPOT Image Corporation Customer Service 703/620-2200. ERIM's aircraft multispectral information file has been generated from a number of projects, and includes information archived at ERIM, those of other contractors and 
the government. Many of the images and digital data bases involved are of relatively high resolution. (Further information is available).

Table 2.1 shows the number of "cloud free" ( $<10 \%)$ Landsat (TM and MSS) images found over several DOE sites since 1972. It also shows the number of "cloud-free" images acquired by SPOT since the first SPOT satellite launch in 1986. A Landsat scene covers about $185 \times 185 \mathrm{~km}$ on the ground and SPOT $60 \times 60 \mathrm{~km}$.

Table 2.1. Multispectral Images from LANDSAT, SPOT and Aircraft as of March 1992

\begin{tabular}{||l|c|c|c|c||}
\hline \multirow{2}{*}{ DOE Facility } & $\begin{array}{r}\text { \# of LANDSAT-TM Scenes } \\
\text { (Cloud-Free) }\end{array}$ & \multicolumn{2}{c|}{ \# of SPOT Scenes (Cloud- } \\
& $1972 \cdot 1992$ & $1990-1992$ & $1986-1992$ & $1990-1992$ \\
\cline { 2 - 5 } & 54 & 0 & 212 & 38 \\
\hline Hanford, Washington & 50 & 0 & 42 & 13 \\
\hline Idaho Falls, Idaho & 37 & 3 & 31 & 11 \\
\hline Oak Ridge, Tennessee & 38 & 4 & 34 & 8 \\
\hline Fernald, Ohio & 94 & 1 & 71 & 17 \\
\hline Rocky Flats, Colorado & 68 & 5 & 31 & 9 \\
\hline Savannah River, Georgia & 87 & 1 & 14 & 9 \\
\hline Los Alamos, New Mexico - N & 71 & 0 & 14 & 10 \\
\hline Los Alamos, New Mexico - S & 90 & 0 & 146 & 72 \\
\hline Nevada Test Site, Nevada - NN & 127 & 0 & 176 & 84 \\
\hline Nevada Test Site, Nevada - NW & 124 & 0 & 235 & 100 \\
\hline Nevada Test Site, Nevada - NE & 150 & 0 & 81 & 33 \\
\hline Nevada Test Site, Nevada - SW & 123 & 1 & 123 & 56 \\
\hline Nevada Test Site, Nevada - SE & & & & \multicolumn{2}{|c||}{} \\
\hline
\end{tabular}

A number of airborne multispectral (MS) scanner collections have been made over DOE facilities, the majority by EG\&G. ERIM has MS scanner data over Savannah River and Nevada Test Site from its M7 instrument. Most aircraft scenes cover a smaller area on the ground than a SPOT scene. The area usually depends on the image resolution. Details about all of these data are available. 


\subsubsection{Aircraft Data}

A variety of other historical data elements are available. World War II aerial photos (some of which may still be classified) can be obtained from the National Archives. One may have to obtain authority to review the image data. The U.S. Department of Agriculture (USDA) Soil Conservation Service (SCS) and the Agricultural Stabilization and Conservation Service (ASCS) both possess image repositories that range back into the 1950 s through the 1980 s.

Even if those data do not cover the DOE sites, the USDA agencies may have data that could help define the properties of the surrounding areas. Photographic data is available through the USDA Aerial Photographic Field Office in Salt Lake City, Utah, at 801/524-5856. They have color IR and black and white photography of the U.S.available at scales from 1:20K to $1: 60 \mathrm{~K}$. Prices are $\$ 5$ per photo index and $\$ 4$ per line index. Currently, it takes about $4-6$ weeks to process a request.

More recent photographic image data can be obtained from the National High Altitude Photography (NHAP) and the National Aerial Photography (NAP) repositories. Both of these photo repositories are maintained by the EROS Data Center (EDC), of the U.S. Geological Survey. States and local authorities also may have image data of the areas surrounding the DOE reservations/restricted sites and possibly of areas within the boundaries of the sites as well.

NHAP 1:40K scale black and white and color IR products acquired between 1980 and 1987 may be located by contacting the EDC in Sioux Falls, South Dakota, 605/594-6969. The EDC also has NAP Program Imagery which is mostly black and white flown between 1987 and the present at 1:20K scale. NAP is not complete so it may not be available for specific areas. The EDC also has NASA Large Format Camera and Skylab S-190B photographic data. It acts as the agent for acquisition of Soviet data, but not other foreign data, for federal agencies. Prices are $\$ 6$ for a black and white contact print, and up to $\$ 65$ for a $40^{\prime \prime} \times 40^{\prime \prime}$ color enlargement. Normally it requires two to three weeks to comply with a request.

The U.S. Environmental Protection Agency (EPA) is known to have flown several aerial photography collection missions in the early 1970s using the RF-4C with multiple cameras and color film types to reveal pollutants being dumped into major waterways. One of the authors of the report in-hand personally flew one such mission from 
Puget Sound to Lake Washington waterways in 1974 and knows of collections in the San Francisco Bay area. There may be others; thus, this data source should be examined further.

Further information can be obtained from the EPA's Environmental Photographic Interpretation Center (EPIC) at Vint Hill Farms Station, near Warrenton, Virginia at 703/349-8970. It has a limited coverage of 1:3K to $1: 12 \mathrm{~K}$ scale imagery. This photography can be relatively expensive but the EPIC can do a search of the data base to tell whether it has coverage quickly. The contracting and copying of data will take additional time. EPIC has color and color IR products including the RF-4C imagery mentioned above.

\subsubsection{Needed Work}

For the satellites systems mentioned in 2.1.1, a computerized data search should be done using the coordinates of each DOE site. This should yield enough relevant information to decide which images to view. For aircraft data, the participants in collections should be consulted to obtain a list of dates and sites. Making such a list will be relatively easy, but obtaining detailed information may require considerable effort.

Having located image sources, the next step is to focus on image content. It is important to make clear what is expected to be extracted from images to "discover" and "characterize" waste sites. The following definitions could be used:

\section{Discover}

- to detect waste sites, and

- to estimate areal extent of waste sites;

\section{Characterize}

- to locate pit or trench boundaries,

- to estimate depth of disturbed (excavated and backfilled) soil,

- to locate buried containers in three-dimensions,

- to estimate container contents,

- to determine whether containers are leaking,

- to locate contaminants from leaking containers in three-dimensions,

- to estimate environmental impact of waste sites upon adjoining lands, and

- to estimate geological structure and hydrological properties of the waste sites and their immediate vicinity, including depth to ground water. 
It is essential that image analysts and phenomenologists visually sample each type of data to assess potential value in terms of these definitions. Acquisition of imagery should proceed on the basis of their recommendations.

\subsection{Current Capabilities Description}

This section provides a discussion of remote sensing systems by example. First, Landsat and SPOT are discussed; they are now being used for a number of environmental assessments including waste site discovery and characterization.

\subsubsection{Landsat and SPOT}

Landsat and SPOT are multispectral systems that operate in the spectral regions shown in Table 2.2. This table, based, in part, on Table 12-11 of the Manual of Remote Sensing (pg. 548; see section 2.3, this report), gives a convenient reminder of what bands of the spectrum give what environmentally relevant information, and of the detector types currently required to exploit this information. The Landsat series began with the launch of Landsat 1 in 1972. Landsats 1 and 2 carried a Multispectral Scanner (MSS) and a 3-band Return Beam Vidicon (RBV) system. Landsat 3 carried an MSS and a higher resolution panchromatic RBV system. ${ }^{2}$ Landsat 4, launched in 1982, carried an MSS and the Thematic Mapper (TM), which provided a major increase in capabilities. Landsat 5 is a duplicate of Landsat 4. Landsat 6, carrying an Enhanced Thematic Mapper (ETM; see Table 2.4l, but no MSS, is scheduled for launch in January 1993. Table 2.3 (based on Table $12-12$ of the Manual of Remote Sensing, pg. 549) shows the seven bands of the TM sensor on Landsats 4 and 5, along with Instantaneous Field of View (IFOV) ${ }^{3}$ in meters. Table 2.4 gives comparative information, Landsat MSS vs. TM versus SPOT.

As presented in section 2.1 of this report, historical Landsat TM and SPOT data can easily be obtained; the Landsat MSS database is both longer in duration and more extensive, but less reliably accessible. Data from the TM and SPOT systems can be merged to produce composite images having the benefits of the spectral and spatial characteristics of each system. Change detection can also be performed with each system's imagery and

${ }^{2}$ The 3-band RBV system is regarded as a technical failure. The panchromatic RBV system does not appear to have been a technical failure, but has not been extensively used.

${ }^{3}$ The IFOV is the smallest area on the ground for which the instrument reports a value of radiance. 
between TM and SPOT. Algarithms are available for land use categorization/classification with special features such as seasonal corrections and routines to emphasize changes of interest.

There are a number of other multispectral systems, mostly with coarser resolution than TM and SPOT along with satellites having other types of sensors such as radar, as well as airborne systems.

\subsubsection{Catalogue}

This section contains partial catalogues of data from some currently available systems. They are not all inclusive having been gathered only from information sources readily available to ERIM. It is recommended that these types of charts be completed, along with the search for imagery discussed in Section 2.1. This is not a large effort, especially if approached "top down" so that details are gathered only for those systems with high promise for remote sensing of waste sites.

Table 2.5 shows Landsat and SPOT, as well as other multispectral imaging satellite systems. Table 2.6 is a catalogue of radar imaging satellite systems. There are also a number of airborne multispectral and radar systems. Table 2.7 is a catalogue for airborne radar. Such a table could be prepared for airborne multispectral systems. A number of satellites and aircraft carry or have carried film cameras and a few examples are given in Table 2.8 . 
Table 2.2. Spectral Regions

\begin{tabular}{|l|c|l|l|}
\hline Region & $\begin{array}{c}\text { Wavelength } \\
(\mu \mathrm{m})\end{array}$ & \multicolumn{1}{|c|}{ Detectors } & \multicolumn{1}{|c|}{ Phenomenology } \\
\hline Ultraviolet & $0.3-0.4$ & $\begin{array}{l}\text { Photographic film, bird and insect } \\
\text { vision }\end{array}$ & $\begin{array}{l}\text { Vegetation, especially flowers, shadows filled in by } \\
\text { diffuse illumination }\end{array}$ \\
\hline Visible & $0.4-0.7$ & $\begin{array}{l}\text { Human vision, silicon detectors, } \\
\text { photographic film }\end{array}$ & $\begin{array}{l}\text { Natural/true color composite images, water } \\
\text { penetration, chlorophyll reflection/absorption }\end{array}$ \\
\hline $\begin{array}{l}\text { Near Infrared } \\
\text { Short-Wave IR } \\
\text { (SWIR) }\end{array}$ & $\begin{array}{l}\text { Silicon detectors, IR sensitive film } \\
\text { Reflection from internal cell structure of plant cells, } \\
\text { health and vigor or stress of plants }\end{array}$ \\
\hline $\begin{array}{l}\text { Mid-Wave IR } \\
\text { (MWIR) }\end{array}$ & $3.0-2.5$ & $\begin{array}{l}\text { Lead Sulfide, Platinum Silicide } \\
\text { Schottky barrier diodes }\end{array}$ & $\begin{array}{l}\text { Water content, snow/ice/cloud discrimination, } \\
\text { geology, emission from hot (450 K or more) objects, } \\
\text { wide range of other applications }\end{array}$ \\
\hline $\begin{array}{l}\text { Long-Wave IR } \\
\text { LWIR) }\end{array}$ & $8.0-14.0$ & $\begin{array}{l}\text { Indium Antimonide, Mercury } \\
\text { Cadmium Telluride }\end{array}$ & $\begin{array}{l}\text { Mixture of reflected and emitted radiation from } \\
\text { warm objects }\end{array}$ \\
\hline
\end{tabular}

Table 2.3. Landsat Thematic Mapper Bands

\begin{tabular}{|l|c|c|c|}
\cline { 2 - 4 } \multicolumn{1}{c|}{} & \multicolumn{2}{c|}{ Wavelength $(\mu \mathrm{m})$} & IFOV $^{4}(\mathrm{~m})$ \\
\hline Band & Lower & Upper & 30 \\
\hline 1 - blue & 0.45 & 0.52 & 30 \\
\hline 2 - green & 0.52 & 0.60 & 30 \\
\hline 3 - red & 0.63 & 0.69 & 30 \\
\hline 4 - NIR & 0.75 & 0.90 & 30 \\
\hline 5 - SWIR & 1.55 & 1.75 & 120 \\
\hline $6 \cdot$ LWIR & 10.4 & 12.5 & 30 \\
\hline 7 SWIR & 2.08 & 2.35 & \\
\hline
\end{tabular}

${ }^{4}$ Instantaneous Field of View; the smallest ground area for which the sensor makes a discrete measurement. 
Table 2.4. Comparison of Landsat Multispectral Scanner, Landsat Thematic Mapper, and SPOT HRV Sensors

Landsat Multispectral Scanner

Spectral Range: $0.5-1.1 \mu \mathrm{m}$

Number of Spectral Bands: 4 (2 V, 2 NIR)

Spectral Bandwidth: $0.1 \mu \mathrm{m}$ (V and NIR) to $0.3 \mu \mathrm{m}$ (NIR)

Instantaneous Field of View ${ }^{5}$ : 79 meter

Ground Swath Width: $185 \mathrm{~km}$

Radiometric Resolution: 6 bits

Data Rate: 15 Mbps

Platform: Landsat Spacecraft (916 km altitude)

Landsat Thematic Mapper

Spectral Range: 0.45 to $13 \mu \mathrm{m}$

Number of Spectral Bands: 7 (3 V, 1 NIR, 2 SWIR, 1 LWIR)*

Spectral Bandwidth: $0.06 \mu \mathrm{m}$ (V) to $4.5 \mu \mathrm{m}$ (LWIR)

Instantaneous Field of View: 30 meter* $(120 \mathrm{~m}$ for $[W I R)$

Ground Swath Width: $185 \mathrm{~km}$

Radiometric Resolution: 8 bits*

Data Rate: 85 Mbps

Platform: Landsat Spacecraft (705 km altitude)

*Plus an additional Panchromatic band $(0.4$ to $0.9 \mu \mathrm{m})$

with 15 meter ground resolution on Landsat 6

SPOT

Spectral Range: 0.50 to $0.90 \mu \mathrm{m}$

Number of Spectral Bands: 3 (2 V, 1 NIR) plus Panchromatic

Spectral Bandwidth: $0.08 \mu \mathrm{m}$ to $0.21 \mu \mathrm{m}$

Instantaneous Field of View: 20 meter (spectral) and $10 \mathrm{~m}$ (panchromatic)

Ground Swath Width: $60 \mathrm{~km}$

Radiometric Resolution: 8 bits

Data Rate: 48 Mbps

Platform: SPOT Spacecraft (832 km altitude)

5 The smallest ground area for which the sensor produces a discrete measurement. 
Table 2.5. Example Catalogue of Spectral Imaging Satellite Systems in the World

\begin{tabular}{|c|c|c|c|c|c|c|c|}
\hline \multirow{2}{*}{$\frac{\text { Name }}{\text { SPOT HRV }}$} & \multirow{2}{*}{$\frac{\text { Country }}{\text { France }}$} & \multicolumn{2}{|c|}{ Band/Spectral Characterization } & \multirow{2}{*}{$\begin{array}{c}\text { Resolution } \\
10 \mathrm{~m} \\
20 \mathrm{~m}\end{array}$} & \multirow{2}{*}{$\begin{array}{c}\begin{array}{c}\text { Average Ground } \\
\text { Coverage/lmage }\end{array} \\
60 \times 60 \mathrm{~km}\end{array}$} & \multirow{2}{*}{$\frac{\begin{array}{c}\text { Part of World } \\
\text { Covered }\end{array}}{\text { all }}$} & \multirow{2}{*}{$\begin{array}{c}\begin{array}{c}\text { Repeat Rate at any } \\
\text { Point on Earth }\end{array} \\
\begin{array}{c}26 \text { da nadir } \\
1,4 \text { or } 5 \text { da off nadir }\end{array}\end{array}$} \\
\hline & & $\begin{array}{r}1 \\
\text { or } 3\end{array}$ & $\begin{array}{l}\text { Panchromatic } \\
\text { VNIR }\end{array}$ & & & & \\
\hline -. & India & .. & (Landsat MSS-like) & .- & .. & all & $44 \mathrm{da}$ \\
\hline $\begin{array}{l}\text { JERS.1 } \\
\text { (scheduled launch } \\
\text { 2/92, research } \\
\text { satellite) }\end{array}$ & Japan & 8 & $\begin{array}{l}\text { VNIR (4) } \\
\text { SWIR (4) } \\
\text { (one pair stereo) } \\
\text { SAR (L band) }\end{array}$ & $\begin{array}{c}18 \times 24 \mathrm{~m} \\
18 \mathrm{~m}\end{array}$ & $75 \times 75 \mathrm{~km}$ & all & 44 da \\
\hline MOS - 1 (MESSR) & Japan & 4 & VNIR & $50 \mathrm{~m}$ & $100 \times 100 \mathrm{~km}$ & all & 17 da \\
\hline MOS - 1 (VTIR) & Japan & 4 & $\begin{array}{l}V(1) \\
\operatorname{TIR}(3)\end{array}$ & $\begin{array}{l}900 \mathrm{~m} \\
2700 \mathrm{~m}\end{array}$ & $1500 \times 1500 \mathrm{~km}$ & all & 1.2 da (?) \\
\hline AVHRR & USA & 5 & $\begin{array}{l}\text { VNIR (2) } \\
\text { TIR (3) }\end{array}$ & $1.1 \mathrm{~km}$ & $1500 \times 1500 \mathrm{~km}$ & all & $1.2 \mathrm{da}$ \\
\hline Landsat MSS & USA & 4 & VNIR & $79 m$ & $\begin{array}{c}185 \times 185 \mathrm{~km} \\
(100 \times 100 \mathrm{nmi})\end{array}$ & all & $16 \mathrm{da}$ \\
\hline Landsat TM & USA & 7 & $\begin{array}{l}\text { VNIR (4) } \\
\text { SWIR (2) } \\
\text { TIR (1) }\end{array}$ & $\begin{array}{c}30 \mathrm{~m} \\
30 \mathrm{~m} \\
120 \mathrm{~m}\end{array}$ & $\begin{array}{c}185 \times 185 \mathrm{~km} \\
(100 \times 100 \mathrm{nmi})\end{array}$ & all & $16 \mathrm{da}$ \\
\hline .. & "Soviet" & .* & (Landsat MSS-like) & .. & -- & -. & -. \\
\hline
\end{tabular}

\footnotetext{
${ }^{7}$ All implies all but near polar regions.
} 
Table 2.6. Example Catalogue of Radar Imaging Satellite Systems in the World

\begin{tabular}{|c|c|c|c|c|c|c|}
\hline Name & Country & $\begin{array}{l}\text { Band/Spectral } \\
\text { Characterization }\end{array}$ & Resolution & $\begin{array}{l}\text { Average Ground } \\
\text { Coverage/lmage }\end{array}$ & $\begin{array}{c}\text { Part of World } \\
\text { Covered }\end{array}$ & $\begin{array}{c}\text { Repeat Rate at any } \\
\text { Point on Earth }\end{array}$ \\
\hline Radarsat $^{\theta}$ & Canada & $\mathrm{HH}-5.30 \mathrm{GHz}$ & -. & - & NA & NA \\
\hline ERS-1 & European Space Agency & L-band/W.5.3 GHz & $25.28 \mathrm{~m}$ & $99.6 w(\mathrm{~km})$ & NA & NA \\
\hline JERS-1 & Japan & $\mathrm{HH}-1.275 \mathrm{GHz}$ &.. & - & NA & NA \\
\hline Almaz-1 & "Soviet" & $\mathrm{HH}-3.0 \mathrm{GHz}$ & $15-30 \mathrm{~m}$ & $20.350 / 40 \mathrm{~L}(\mathrm{~km})$ & NA & NA \\
\hline COSMOS 1870 & "Soviet" & S-Band SAR & $25.30 \mathrm{~m}$ & .. & NA & NA \\
\hline EORSAT & "Soviet" & passive used with RORSAT & .. & - & NA & NA \\
\hline OKEAN-1 & "Soviet" & SLR, W, $9.56 \mathrm{GHz}$ & $1.5 \mathrm{~km}$ & $460 \mathrm{~km}$ swath & NA & NA \\
\hline RORSAT & "Soviet" & active non-SAR & $40 \mathrm{~m}$ &. & NA & NA \\
\hline EOS-SAR & USA & $\begin{array}{l}\text { Polar } 1.20 \mathrm{GHz} \\
\text { W,HH } 5.0 \mathrm{GHz} \\
\text { W,HH } 9.0 \mathrm{GHZ}\end{array}$ & .. & .• & NA & NA \\
\hline Magellan & USA & $2.385 \mathrm{GHz}$ &. & - & Venus & NA \\
\hline SEASAT & USA & $\mathrm{HH}-1.275 \mathrm{GHz}$ & - & - & NA & NA \\
\hline SIR-A & USA & L-band / HH-1.275 GHz & $20 \cdot 30 \mathrm{~m}$ & $\ddot{-}$ & NA & NA \\
\hline SIR.B & USA & L-band / HH-1.275 GHz & $20.30 \mathrm{~m}$ & - & NA & NA \\
\hline SIR-CIX.SAR ${ }^{10}$ & USA & $\begin{array}{c}\text { Polar }-1.25 \mathrm{GHz} \\
\text { Polar }-5.30 \mathrm{GHz} \\
\mathrm{W} \cdot 9.606 \mathrm{~Hz} \text { (X.SAR) }\end{array}$ & $30 \mathrm{~m}$ & $\begin{array}{c}15.90 \mathrm{w}(\mathrm{km}) \\
15.40 \mathrm{w}(\mathrm{km}) \text { for X.SAR }\end{array}$ & NA & NA \\
\hline
\end{tabular}

${ }^{8}$ Scheduled for launch in 1995.

${ }^{9}$ Unfunded due to high cost; Phase B design exists.

${ }^{10}$ Awaiting flight in 1993. 
Table 2.7. Example Catalogue of Radar Imaging Aircraft Systems in the World

\begin{tabular}{|c|c|c|c|c|c|c|}
\hline Name & Country & Band/Spectral Characteristics & Resolution & $\begin{array}{l}\text { Average Ground } \\
\text { Coveragellmage }\end{array}$ & $\begin{array}{c}\text { Part of World } \\
\text { Covered }\end{array}$ & $\begin{array}{c}\text { Repeat Rate at Any Pt } \\
\text { on Earth }\end{array}$ \\
\hline AuSAR & Australia & $X$-band & -. & - & .. & .. \\
\hline CCRS/(CV-580) & Canada & $\begin{array}{c}\text { HHIV?/15.3 GHZ } \\
\text { Polar/X-band } \\
\end{array}$ & $5.20 \mathrm{~m}$ & $16.463(\mathrm{~km})$ & -- & .. \\
\hline IRIS & Canada & $X \cdot B$ and SAR & .. & .. & -- & -. \\
\hline CASSAR & Chine & Polar/X-band & -. & -- & -. & .. \\
\hline VARAN-S & France & HH/WV/9.375 GHz & $3 m$ & $11.9(\mathrm{~km})$ & .. & .. \\
\hline E-SAR (D0228) & Germany & Polar?h, C\&X-band & $2 m$ & $3 \mathrm{~km}$ & .. & .. \\
\hline AMRS/Soviet (IL-18 & "Soviet" & $\begin{array}{c}\text { Polar/L-band SAR-25 } \\
\text { Polar/.167 GHz SAR } 180 \\
\text { W/X-band SLR-3 } \\
\text { HHIW Ku-band SLR-0.8 }\end{array}$ & $15-25 \mathrm{~m}$ & $30-120(\mathrm{~km})$ & .. & .. \\
\hline RSRE - SAR & U.K & $X$-band & .. & .. & -. & - \\
\hline DCS/ERIM (CV.580) & USA & Ku-band & .. & .. & .. & .. \\
\hline NADC/ERIM (P-3) & USA & $\begin{array}{c}\text { Polar } 1.25 \mathrm{GHz} \\
\text { Polar } / 5 \mathrm{GHz} \\
\text { Polar } 110 \mathrm{GHz} \\
\end{array}$ & $2.4 \mathrm{~m}$ & .. & .. & .. \\
\hline NASA|JPL (CV-990) & USA & Polar/1.224 GHz & $10.13 \mathrm{~m}$ & $7 w(\mathrm{~km})$ & - & .. \\
\hline NASA/JPL (DC-8) & USA & $\begin{array}{c}\text { Polar } 10.44 \mathrm{GHz} \\
\text { Polar/1.25 GHz } \\
\text { Polar/5 GHz }\end{array}$ & $10-13 \mathrm{~m}$ & $10 w(\mathrm{~km})$ & .. & .. \\
\hline SARLAB (CV.580) & USA & .. & .. & .. & .. & .. \\
\hline PHARUS/Delft $U$ of $T$ & & Polar/C-band & .. & .. & .. & .. \\
\hline
\end{tabular}


Table 2.8. Example Catalogue of Film Camera Imaging Satellite or Aircraft Systems in the World

\begin{tabular}{|c|c|c|c|c|c|c|}
\hline Name & Country & $\begin{array}{l}\text { Band/Spectral } \\
\text { Characteristics }\end{array}$ & Resolution & $\begin{array}{l}\text { Average Ground } \\
\text { Coverage/Image }\end{array}$ & $\begin{array}{c}\text { Part of World } \\
\text { Covered }\end{array}$ & $\begin{array}{l}\text { Repeat Rate at } \\
\text { Any Pt on Earth }\end{array}$ \\
\hline Film Cameras Available via Soyuzkarta & "Soviet" & - & $5 \mathrm{~m} /$ line pair & .. & $\begin{array}{l}\text { All but USSR } \\
\text { and poles }\end{array}$ & -- \\
\hline S.190A Skylab 1973 & USA & $\begin{array}{c}\text { Multispectral B\&W } \\
\text { Color } \\
\text { CIR }\end{array}$ & 80 m/line pair & .- & -. & - \\
\hline S-190B Skylab 1973 & USA & $\begin{array}{l}\text { Color } \\
\text { CIR } \\
\text { B\&W }\end{array}$ & $10 \mathrm{~m} / \mathrm{line}$ pair & .. & -. & -. \\
\hline $\begin{array}{l}\text { National High Altitude Photographic Program (NHAP) } \\
\text { on U.2 type }\end{array}$ & USA & $\begin{array}{l}\text { Natural Color } \\
\quad \text { CIR }\end{array}$ & 2 feet & $10 \times 10$ miles & USA & 3 years \\
\hline Large format camera on Space Shuttle 1985 & -. & $\begin{array}{l}\text { Color } \\
\text { CIR } \\
\text { B \& W }\end{array}$ & Best is $5 \mathrm{~m} /$ line-pair &. & .. & .. \\
\hline
\end{tabular}




\subsubsection{Availability}

The number of systems listed points to an important fact: there are a number of standard remote sensing systems available, many of which collect imagery that can be obtained by the public. However, only if the imagery can be used in waste discovery and characterization is it relevant to the discussion here. Section 3 develops a method for determining what is useful. To complete the information provided in Section 2, a brief bibliography of ERIM's selected readings on remote sensing for environment is included next.

\subsection{JOURNALS/TEXTS ON REMOTE SENSING - A SELECTED BIBLIOGRAPHY}

A Guide to Remote Sensing: Interpreting Images of the Earth. S.A. Drury, Oxford University Press, 1990

Applied Remote Sensing. C.P. Lo. Longman, 1986.

Classification of Remotely Sensed Images. Ian L. Thomas. Adam Hilger, 1987

Geocarto International. ISSN 1010-6049.

Geographic Information Systems. Aster Publishing. ISSN 1051-9858.

GIS World. ISSN 0897-5507.

IEEE Transactions on Geoscience and Remote Sensing. (ISSN 0196-2892)

Image Interpretation in Geology. S.A. Drury. Allen and Unwin, 1987.

International Journal of Remote Sensing. Taylor DeFrancis. ISSN 0143-1161.

International Journal of Remote Sensing. Taylor DeFrancis. ISSN 0269-3798.

Introduction to Remote Sensing. James B. Campbell. Guilford Press, 1987. 
Introduction to the Physics and Techniques of Remote Sensing. Charles Elachi, Wiley, 1987.

Introductory Digital Image Processing: A Remote Sensing Perspective. John R. Jensen. Prentice-Hall, 1986.

Manual of Remote Sensing, 2nd Edition. R.N. Colwell, D.S. Simonett, F.T. Ulaby, J.E. Estes, G.A. Thorley. American Society of Photogrammetry, Falls Church, VA. ISBN 0.937294.41-1 (Volume 1). ISBN 0. 937294-42-X (Volume 2).

Photogrammetric Engineering and Remote Sensing. American Society of Photogrammetry and Remote Sensing. ISSN 009.1112.

Physical Fundamentals of Remote Sensing. Erwin Shanda. Springer-Verlag, 1986.

Physical Principles of Remote Sensing. W.G. Recs. Cambridge University Press, 1990.

Principles of Remote Sensing. Paul J. Curran, Longman, 1985.

Remote Sensing and Image Interpretation. Thomas M. Lillesand. Wiley, 1987.

Remote Sensing Digital Image Analysis: An Intraduction. J.A. Richards. Springer-Verlag, 1986.

Remote Sensing in Hydrology. E.T. Engman. Chapman and Hall, 1991.

Remote Sensing in Soil Science. Michel A. Mulders. Elsevier, 1987.

Remote Sensing of Environment. Elsevier. ISSN 0034-4257.

Remote Sensing of Ice and Snow. Dorothy K. Hall. Chapman and Hall, 1985.

Remote Sensing: Methods and Applications. Michael R. Hord, 1986.

Remote Sensing: Principles and Interpretation. Floyd F. Sabins. Elsevier, 1987. 


\subsection{A SYSTEMS APPROACH}

It is the opinion of ERIM, as well as most others who have considered sensor capabilities to address this problem, that there is no one "magic" trick for a remote sensing application that satisfies the DOE detection and characterization task. Remote sensing has much to contribute, but the real task is to decide which sensor(s) to use and how. There is a real need for a systems analysis of the total problem; that is, what are the problems, what can solve them, how well, and for how much effort? The systems analysis discussed here involves only non-invasive optical and radio-wave methods. At most sites, invasive and other remote sensing techniques will be used as well, so an additional study should be conducted on the trade-offs indicated and sampling procedures that result from considering all sensing approaches.

A critical element in the systems study is to compare the actual components of the problem which must be solved to phenomena that sensors can address to the specific sensors that may provide the solution. Section 3.1 gives an example of matching problems to sensors and Section 3.2 discusses a cost benefit methodology to compare alternative acceptable solutions. Section 3.3 outlines a plan for evaluating sensors in systematically characterizing a site. Section 3.4 addresses a time schedule for the plan.

\subsection{EXAMPLE OF MATCHING PROBLEMS TO SENSORS}

An example assessment was made by a group of ERIM sensor technologists to demonstrate the need to match problems to sensor solutions. Table 3.1 shows one of many "matrices," generated in that assessment. The first column lists the "DOE Problem Set" or problems listed in DOE's RDDT\&E document, 12.2.1.6 being the need for remote, in situ, or other on-site methods for local characterization of contaminants). The "problem elements" are the topics listed earlier in this report as problems to be addressed at waste sites. The next column on the table gives "information elements" that represent specific information which is needed to provide answers/inputs to the problem elements. Table 3.1 focuses on subsurface contaminants (problem element) and location of tanks (information element).

The "target observables" were selected by ERIM as being those that represent the physical target phenomena which may be used to locate buried tanks. These were matched to "signature observables" or the information provided by the sensor. The "sensor" column shows typical sensors that could provide the information. A 
Table 3-1. Example of Matching Target Observables to Signature Observables to Sensors

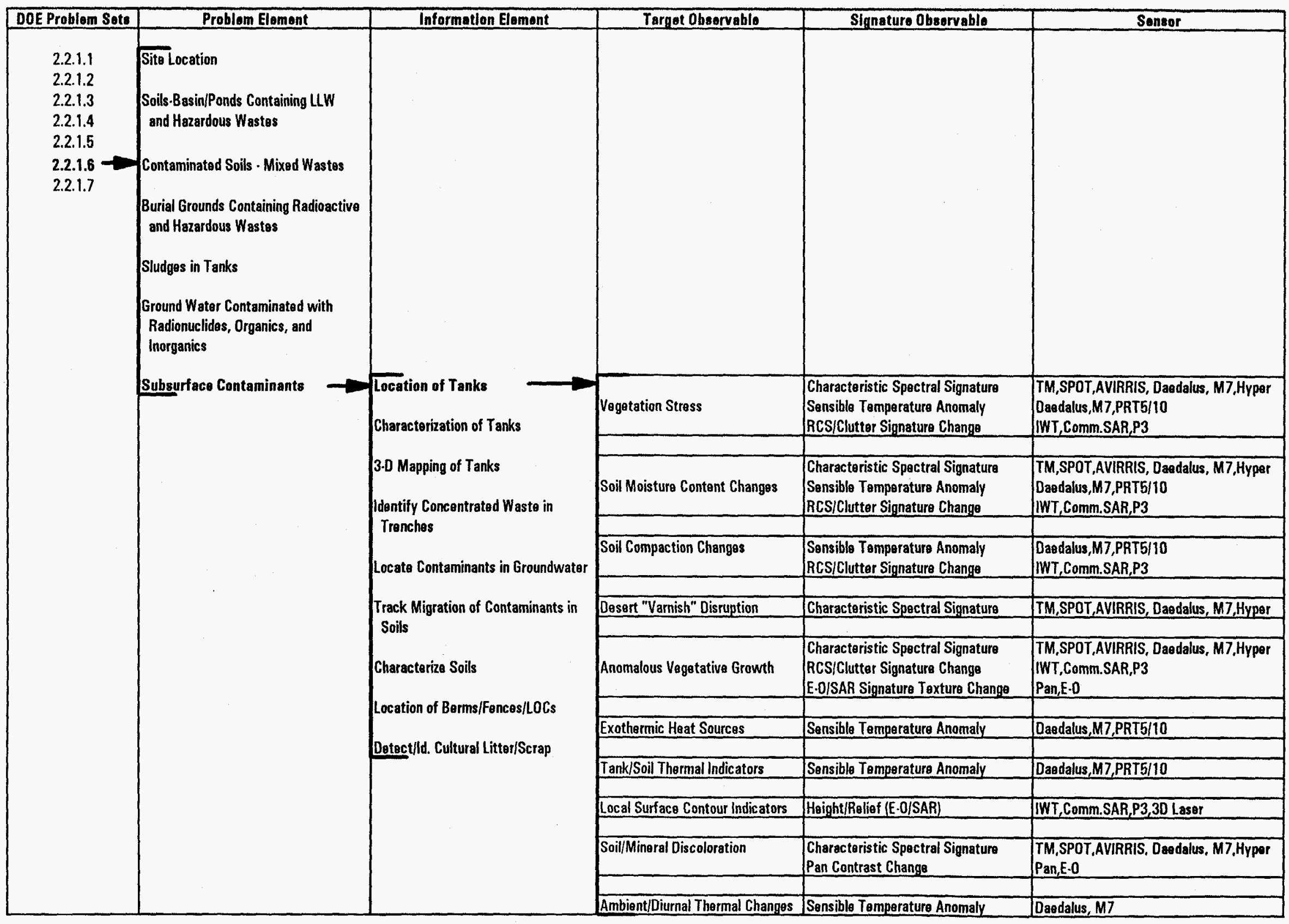


Table 3.2. Definitions of Sensor Codes listed in the far right column of Table 3.1

AVIRIS

Airborne Visible \& InfraRed Imaging Spectrometer. An image-forming multispectral scanner, operated on an aircraft by NASA JPL, having over 100 spectral channels. One of the first "hyperspectral scanners."

Comm. SAR, P3 Any of a number of commercially available SAR sensors such as the one flown by DOD's P3 aircraft.

Daedalus

Daedalus Enterprises manufactures a line of multispectral scanners for airborne operation.

Hyper

Hyperspectral scanners. A generic imaging scanner that operates with about a hundred to a few hundred spectral channels, compared to a multispectral scanner which has two to a few tens of channels.

IWT

A Convair 580T aircraft and SAR system operated by ERIM as an Intelligent Weapons Technology testbed.

M7

A multispectral scanner with 16 channels developed by ERIM. The channels are located in the UV-visible, near IR, short-wave IR, and thermal IR regions of the spectrum. A large measure of flexibility to shift/relocate the spectral location of the channels exists. Currently flown on ERIM aircraft.

Pan E-O

A generic panchromatic E-O camera on aircraft platform.

PRT5/10

Hand held thermal infrared radiation thermometers. The Barnes Engineering PRT 5 and 10, although no longer available, are prototypical of this class of instruments.

SPOT

The SPOT multispectral satellite.

TM

The Landsat Thematic Mapper (TM).

3-0 Laser

A generic 3-0 Laser Radar.

ground rule for this exercise was that the sensors listed had to be currently operational with products demonstratable now or expected to be so within two years. Sensors selected were meant to be illustrative of a type, not necessarily the most preferred of a type. Definitions of sensor codes are given on Table 3.2. Details of this work and all matrices are given in the appendix.

It is essential that this type of logic be exercised to make useful recommendations about a sensor suite for waste site problems. The type of matrix shown in Table 3.1 identifies the sensors that can provide the "benefit". Next, the cost of sensors is discussed. 


\subsection{A COST-BENEFIT METHODOLOGY}

Having identified the sensor(s) that address the problem(s), the cost-benefit analysis should proceed. This requires that benefits and costs be quantified. Although the quantifications of benefits and costs often seem artificial or contrived and at best, approximate, ERIM has found that this type of analysis is very useful in providing a framework to make decisions about what future technologies to give priority funding.

To do the analysis, potential sensor solutions to each problem are assigned a benefit rating and cost value. Some examples of benefit are: percentage of the problem that would be expected to be solved by the sensor; or categorical ratings of good/OK/bad when compared to other possible sensors; or amount in square meters of waste site area "characterized." Cost can also be very approximate; order of magnitude dollars are often adequate for decision making. Sometimes even categories such as high/medium/low are adequate. However, both development and operational costs need to be considered for technology development comparisons.

Having assigned each problem such as "tank location indicated by soil moisture content change" and each sensor solution such as "characteristic spectral signature from M7" a benefit and cost, then a DOE "scenario" would be chosen. The scenario is based on knowledge of the site problems, policies and priorities, and represents the relative value of each of the various waste site problems. One way of quantifying the scenario is to assign a percentage of the total problem that each problem represents. A priority ranking for each problem can also be used. Again, these only need be approximate to help guide the analysis.

To compare one sensor suite against another, quantities like percentage of the total problem solved are compared to cost, for each suite. To assess the benefit/cost of new technology, the expected benefit of some new development is compared to that for existing technology being sure to include operational plus development costs. To evaluate more than one new technology, their relative benefit/cost ratios are compared.

\subsection{PLAN FOR EVALUATING SENSOR USE IN DISCOVERY AND CHARACTERIZATION OF WASTE SITES}

The following plan is an implementation of systems engineering methodology that allows intervention at selected intervals to determine whether the activity should proceed. It is recommended that this type of procedure be implemented as a "test characterization." The plan is organized in nine steps, some of which have already been partially completed by the DOE. 
Step 1 . Select one or more suitable GIS. Because it is likely that data will be forthcoming from a number of sources, it is suggested that a GIS be the central receiver of all data. In this way, information can be geo. coded and tracked over time. Information would include historical data on waste site disposals and other events, geological/hydrological profiles, cultural features, imagery and maps. It is likely that more than one GIS will be needed and even that multiple GIS may be needed for some sites in order to handle the mix of high and low resolution, and point, vector, and raster data. These GIS should be compatible with each other. A modest image processing set-up to produce change detection images would be very useful. Determination of data analysis needs and restoration personnel's requirements should be conducted to determine what features would be useful for them.

Step 2 . Select sites for test cases. Selection of several sites vice one is preferred because the process should be demonstrated on a wide variety of contaminant and contaminant storage problems. Also, the site selection should include site(s) where the contaminant and storage media are already well understood and site(s) where contaminants are only believed to be stored. To minimize cost for this test, these sites should be relatively close to each other. Nearly contiguous sites would be ideal, separated enough to avoid interaction among the sites. A separate group of such sites should also be tested where the geographical background (vegetation, climate, soils, hydrology, geology) is different.

Step 3. A comprehensive analysis of the potential observables. This analysis would be conducted through discussions with site specialists, in addition to specialists on the contaminant/storage containers, and specialists on sensors. The purpose of this effort is to identify those phenomena that a sensor may interrogate/collect that could be used as evidence that a contaminant and/or its container are present.

Step 4 - Collect all historical data. Data from interviews with old-timers and others at the sites is needed to obtain historical knowledge. It should be entered into the GIS to generate a temporal analysis of the site. This, along with hydrological, topographical and geological data should yield a substantial understanding of sites and their differences.

Step 5 - Check. At this point, an assessment of the results of the preceding activities should be conducted. The purpose is to review the usefulness of what has been accomplished and whether there is sufficient motivation to continue. 
Step 6 - Comprehensive evaluation of sensor characteristics and sensitivities. At this point, consider and then select the particular sensors that demonstrate capability for discovering and characterizing contaminants and containers present at the test sites. The actual mix would be based on expected cost/benefit criteria.

Step 7 - Second check. A second assessment is suggested at this point because in the next step, image data are collected and the cost of collecting data with sensors is relatively high compared to the previous activities.

Step 8. Collect and analyze data needed to evaluate sensor capabilities. In this step, data are collected. If possible, historical imagery and other information would be used. If not, new collection may be needed. In this step, the process of comparing problems to sensor solutions is verified and validated. The effectiveness of the sensors is assessed individually and in concert with others to provide evidence of newly discovered problems or provide information about known problems.

Step 9 - Implement the process at more sites, as required. It is likely that the test sites do not include some waste problems of interest and do not include all representative geographical areas. The process should be repeated, as required, to include these. Also, another test at a similar facility would be appropriate to evaluate repeatability.

\subsection{TIME SCHEDULE}

In theory, the systems plan just presented assumes that there is adequate time to stop to test a new sensor concept, attempt to collect and merge data to check for practical problems, etc. In this way, maximum information goes forward to select a sensor suite or to a decision to improve a technology. It is rare and certainly not true in this case, that the community can wait one to two years to do the study needed.

There is a need for specialized field experiments to test new proposed sensor-application relationships and for research into sensor/image processing modifications to current technology. There is also a need to demonstrate practical aspects of sensor tasking and to try innovative data merging. Ideally, these activities would follow and be guided by the systems study just described. However, in the interest of time, it is recommended that special sensor investigations and case study demonstrations be done in parallel with the assessment of current sensor systems. 
Thus, it is essential that the results of sensor technology work, systems studies and case study demonstrations be continually integrated. All three types of work have already been initiated and it may be reasonable to merge them about one year from now for an integrated site demonstration (See Figure 3.1).

Section 4.0 contains some of ERIM's ideas about what technologies may be fruitful and Section 5.0 contains recommendations for case study demonstrations. Section 6.0 summarizes report recommendations. 
Figure 3.1. Interplay of Studies

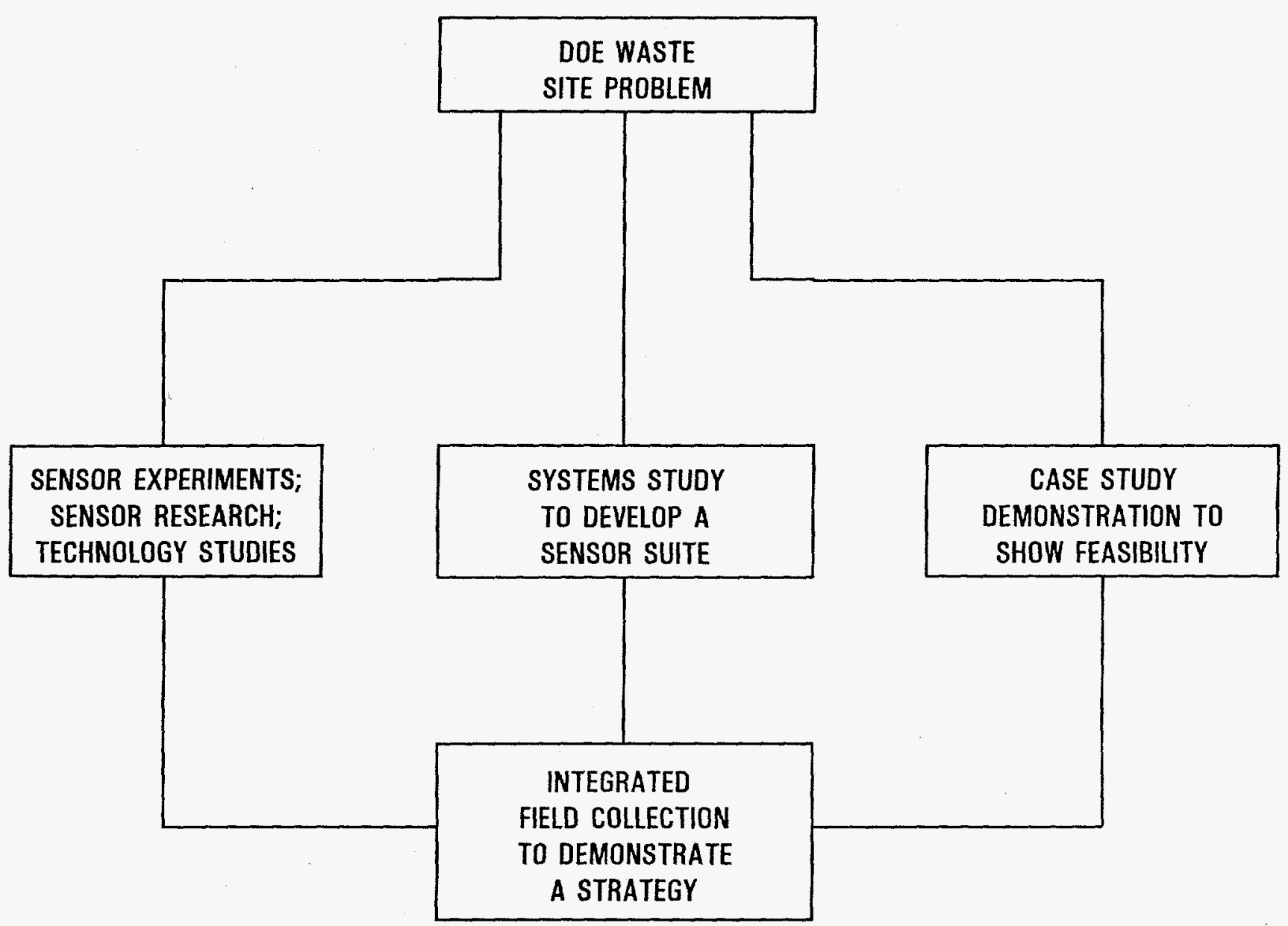




\subsection{SPECIAL SENSOR TECHNOLOGY/PROCESSING}

It is recommended that a cross-section of the remote sensing community and sensor developers/phenomenologists be contacted to suggest and prioritize sensor approaches for this problem. Of particular interest is what sensors would be particularly useful, what new development is needed, and what new data analysis might be suggested. Because of the time-critical nature of the problem it should be limited to sensors already available or in development, and not "blue sky" approaches.

\subsection{AN EXAMPLE}

Table 4.1 shows an example of input from ERIM specialists. The observables shown on the table were presented to the specialists who were asked to suggest "good" sensor solutions, noting whether the technology was available now, and noting their confidence in the suggestion. They were told to consider the following observables:

- detection of waste sites,

- estimation of the planar dimensions of waste sites,

- location of pit or trench boundaries,

- estimation of depth of disturbed (excavated and backfilled) soil,

- three-dimensional location of buried containers,

- determination of whether containers are leaking, and

- estimation of environmental impact of waste sites upon adjoining lands.

In summary the specialists were most confident or certain that existing multispectral systems could contribute to all observables except those requiring ground penetration. They were also certain about the capability to do the various tasks shown on the table with differential absorption LIDAR as available now, and with laser-induced fluorescence and multispectral LIDAR which are still in development.

The specialists suggested SAR texture analysis, use of multiple frequencies and multiple polarizations to detect sites, estimate site dimensions and locate boundaries as well as evaluate surrounding environmental 
Table 4.1. Example of Method for Comparing Sensor Alternatives

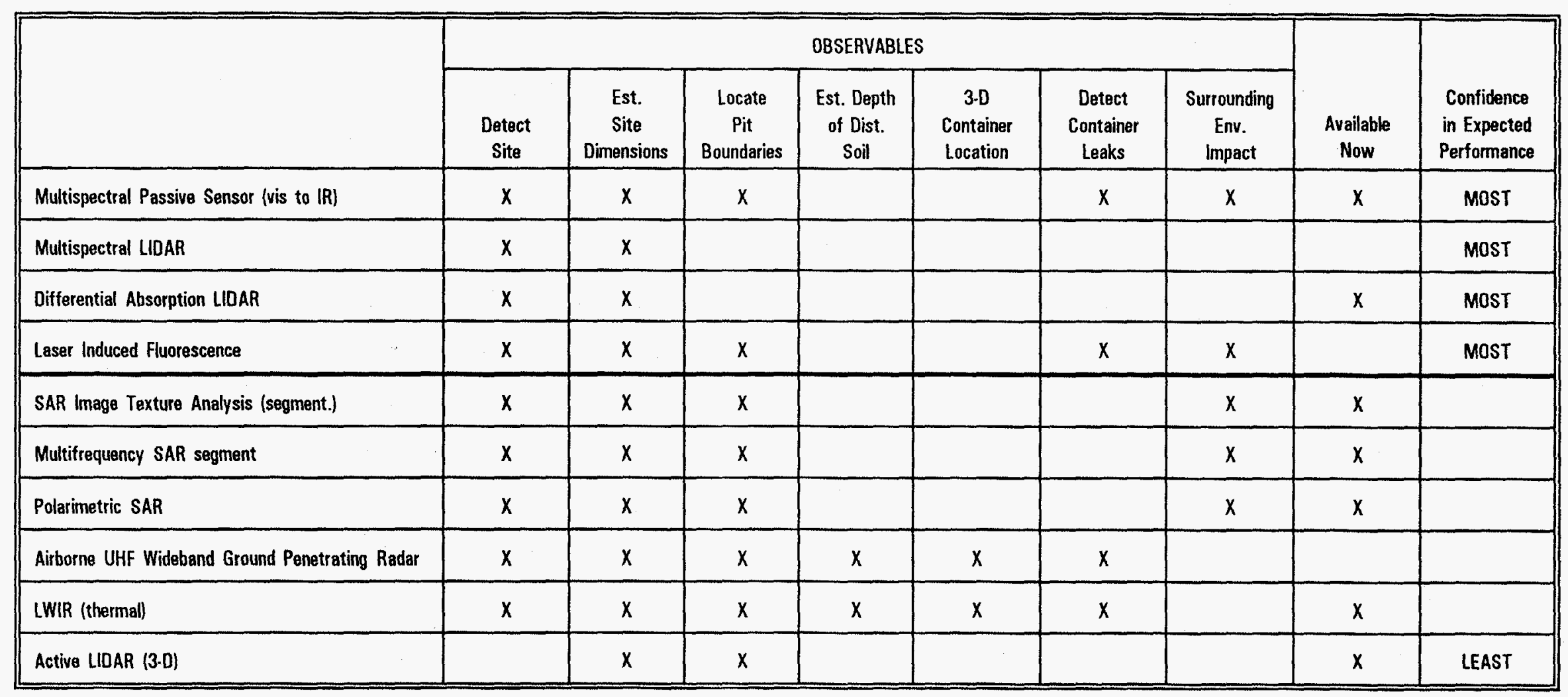


impact. The specialists were moderately confident, but not certain, that these currently available radar technologies would work. They also commented that ground penetrating radar could perform the first three observables while also determining the depth of disturbed soil, 3-D location of containers and detecting container leaks. However, such a radar is not commercially available at this time. Again, they were only moderately confident and felt that controlled experiments are needed to confirm their conjecture.

The specialists were also moderately confident that LWIR (thermal) capabilities could contribute to the detection and location tasks, with technology available now. The ERIM specialists were the least certain about currently available active (3-D) LIDAR sensitivity to locate and estimate dimensions of pits and their boundaries.

These are just examples of the utility of the recommended approach. A comprehensive survey of the community should be conducted as is currently being planned for DOE workshops.

In the process of preparing this report, a number of suggestions have come forward from ERIM specialists. They are presented next, in no particular order.

\subsection{OTHER SUGGESTIONS}

- Develop special FLIR processing to detect change in emitted radiance due to leaking buried tanks.

- Measure changes in the thermal behavior of the area surrounding buried tanks with developing multispectral or hyperspectral sensors.

- Measure differences in the thermal inertia of different waste sites as compared to background.

- Detect areas of heavy metal contamination by multispectral analysis (from aircraft); if area large enough use Landsat or SPOT.

- Detect changes in land contours by repeating surveys using interferometric SAR systems that are being developed.

- Improve data processing from currently available ground penetrating radar to determine whether the sensor has potential to detect buried objects.

- Develop a robotic platform to test for changes in gaseous emissions from tanks.

- Develop an aircraft testbed employing multiple sensors selected especially for waste problems.

- Test the HYDICE or other hyperspectral scanner technologies for detection of a number of chemicals.

- Retrofit sensitive, invasive ground-based chemical detectors on aircraft or other platforms.

- Implement sub-pixel analysis or other pattern recognition/target detection methods on appropriate image data sets.

- Review current Landsat and SPOT data processing, automatic or supervised classification to see what enhancements might be appropriate for waste problems.

- Employ change detection and image fusion technologies with Landsat, SPOT, maps and other imagery (radar, optical). 
- Use a GIS to update maps, categorize and merge data from multiple sensors and data bases.

Much more detail is available on all of these suggestions as well as those of Table 4.1. This detail can be provided on request.

\subsection{TAKING ADVANTAGE OF OTHER STUDIES}

Many environmental surveys based on airborne and satellite-based data have been conducted for county land use/waste disposal inventories, wildife population studies, disease/infestations in forests, agricultural land monitoring and the like. Other studies have been made by DOD and NASA looking for buried objects. These studies have utilized observables similar to those for waste site discovery characterization, so individuals who have been involved in these studies are a resource. It is recommended that selected studies be reviewed and individuals contacted to determine:

- which sensors added what information,

- how sensors were used together,

- how often to revisit an area, and

- what resolutions or spectral bands were needed. 


\subsection{CASE STUDIES}

Two case studies are recommended. One uses historical data and one involves new data collection.

\subsection{CASE STUDY - HISTORICAL DATA}

A recent review of historical imagery, ground truth data, and auxiliary information has shown that good historical information is available for Los Alamos waste sites. Imagery is available from the time the sites began to be used and documentation is good for the historical period. The purpose of a historical case study at Los Alamos would be to demonstrate data fusion methods, that is, how a GIS system could be used to fuse a number of data sources to monitor the sites, detect changes and begin site characterization.

\section{Sources of data are:}

- Multispectral, IR imagery,

- Photography,

- Radar imagery,

- Gamma ray and chemical detection data,

- Ground truth,

- Meteorological, geographical and hydrological data,

- Soil samples,

- Conversations with "old-timers" about waste disposal locations

- Los Alamos remediation project data files, and

- Any relevant scientific experiments that have taken place at the site.

The difficulty here is likely to be which data to include, rather than a lack of data. Special studies should include:

- Demonstrations of use of GIS for site characterization,

- Creative processing of existing imagery to highlight waste problems,

- Image fusion,

- Suggestions of useful graphic output, and

- Indicators of change. 
It should be mentioned that among DOE facilities, Los Alamos does not have the most serious waste problems. However, there are numerous interesting features at the sites, more than are likely to be covered in any case study. As a demonstration of data fusion technology Los Alamos offers an excellent choice because of the good quality of ground truth. Also, since the Los Alamos remediation team is available on a daily basis, the demonstration could be authentic and current.

A preliminary look at the data indicate that there is enough coverage from the various sensor sources to piece together some typical trends to adequately demonstrate a remote sensing methodology. However, to study true synergistic applications, new imagery will have to be collected in a coordinated fashion. To obtain geographic and waste type variation, several sites will have to be considered. The next case study addresses that.

\subsection{CASE STUDY - NEW COLLECTION}

There are numerous reasons for a new data collection and many purposes can be served by a well-planned one. New collections are needed to obtain:

- time coincident coverage by different sensors,

- use of new experimental sensors,

- additional ground truth data, commensurate with the signature and sensing involved

- digital data forms that are not normally saved, such as radar phase histories,

- imagery that is collected frequently enough to observe changing phenomena, and

- imagery that is of the appropriate type to observe the phenomena.

The result of a new collection would be to:

- determine what sensors can adequately and accurately measure which phenomena,

- demonstrate the benefit of data fusion, and

- provide a demonstration of a proposed multisensor/multisource characterization methodology.

A few recommendations for the collection are as follows:

- Good historical data will be important to be able to demonstrate any new change.

- Ground truth is very important to be able to understand the remote sensing data. 
- Existing satellite systems can be tasked cheaply; if budget permits, adding aircraft collection would give flexibility of collection times and opportunities to examine other phenomena and use new experimental sensors.

- Collection should cover all seasons of the year.

- Once set in place, some parts of the collection effort could continue each year.

Finally, each DOE facility offers unique geography and physical plant description with numerous waste sites to be observed. The collection should task a small subsample of waste sites very frequently to observe phenomena that require frequent coverage. A larger sample of the waste sites can be tasked less frequently to observe geographic variation.

\subsection{SCHEDULE}

The demonstration using Los Alamos historical data can begin immediately and could be completed in $2 \cdot 3$ months. The new collection should take one year to cover all seasons and then repeat. About one month should be allocated to solicit collection requests from the various collection participants with an additional month allocated for planning and data requests. Of course, the initiation time depends on the availability of sensors used. 


\subsection{SUMMARY OF RECOMMENDATIONS}

It is unlikely that there is a single remote sensing technique that can, by itself, discover and characterize waste sites. However, it is expected that some requirements can be met using a suite of appropriate sensors along with collateral information. Data fusion, especially based on GIS systems, will likely have high payoff.

At this time, the remote sensing community has not verified a sensor collection/processing strategy for the waste site problem. Rather than concentrating on advanced sensor technology development, it is recommended that existing sensor systems be emphasized including improved packaging and processing techniques. Enviranmental agencies and the military/intelligence community have studied similar problems; it is recommended that DOE obtain their input and involvement.

A systems study is recommended; observables must be defined, matched to sensor capabilities; and a costbenefit analyses made. An inventory of sensors and historical imagery is essential but it needs to be selective. "Old-timers" at the sites are also valuable information sources on site locations and history. First-cut recommendations need to be made about

- What sensor/processing technologies should be examined,

- what GIS systems should be used to combine information, and

- what case study collections should be made.

A recommended approach includes an element of overall area monitoring at relatively low resolution, followed by focussed satellite collection at higher resolution with appropriate ground truth data collection. For area monitoring, improved processing and change detection algorithms for Landsat and SPOT are expected to have high payoff. GIS-created maps from all information and image fusion are also likely to be of benefit.

Sensor solutions that are recommended as having the most promise for the observables discussed in this report are:

- multispectral, especially IR or hyperspectral, for thermal effects, vegetative change, leaks, and contaminants,

- radar for depth, dimension, and texture, and

- LIDAR, laser fluorescence, and hyperspectral for chemical effluents. 
The value of some of these recommendations need to be validated. ERIM also recommends that some thought be given to platforms. While DOE data collections have utilized sensors on low flying aircraft, high flying aircraft, satellites and other means are all possibilities. There is much room for innovation, such as:

- robotic platforms for sensitive (unsafe) areas,

- chemical detectors on aircraft, and

- $\quad$ specially designed aircraft platforms to collect simultaneous signatures of various kinds.

Two case studies are recommended. The first is a Los Alamos historical data study to demonstrate the merging of information to yield new inferences. The second is a new collection to demonstrate sensor capabilities and develop integrated strategies. These practical demonstrations can provide feedback to on-going systems studies and other special sensor experiments or research.

From the two case studies, systems studies and the knowledge gained through pooled data/information/experiments sponsored by all interested agencies, sufficient experience should have been gathered to apply the lessons to other site characterizations. Following a plan similar to the one suggested in section 3.3 , trial characterization should be implemented at selected DOE sites. 
APPENDIX: REQUIREMENTS ANALYSIS 
Table A.1. Definitions of Sensor Codes listed in the far right column of Tables A.9.x.X

AVIRIS

Comm. SAR, P3

Daedalus

Hyper

IWT

M7

Pan E-O

PRT5/10

SPOT

TM

3-D Laser
Airborne Visible \& InfraRed Imaging Spectrometer. An image-forming multispectral scanner, operated on an aircraft by NASA JPL, having over 100 spectral channels. One of the first "hyperspectral scanners."

Any of a number of commercially available SAR sensors such as the one flown by DOD's P3 aircraft.

Daedalus Enterprises manufactures a line of multispectral scanners for airborne operation.

Hyperspectral scanners. A generic imaging scanner that operates with about a hundred to a few hundred spectral channels, compared to a multispectral scanner which has two to a few tens of channels.

A Convair 580T aircraft and SAR system operated by ERIM as an Intelligent Weapons Technology testbed.

A multispectral scanner with 16 channels developed by ERIM. The channels are located in the UV-visible, near IR, short-wave IR, and thermal IR regions of the spectrum. A large measure of flexibility to shift/relocate the spectral location of the channels exists. Currently flown on ERIM aircraft.

A generic panchromatic E-O camera on aircraft platform.

Hand held thermal infrared radiation thermometers. The Barnes Engineering PRT 5 and 10, although no longer available, are prototypical of this class of instruments.

The SPOT multispectral satellite.

The Landsat Thematic Mapper (TM).

A generic 3-D Laser Radar. 
Table A.2 DOE Problem Description

2.2.1.1 Need for Better Characterization of Subsurface Geohydrologic Features and Properties - Characterization of subsurface geology, hydrology, geochemistry/geophysics, and biological activity.

2.2.1.2 Need for Better Characterization and Sampling Strategy - Site characterization, strategic planning for data collection (sampling) and data utilization. Includes geostatistical analyses.

2.2.1.3 Need for Characterization of Inactive Facilities - Design, construction features, current physical condition and contamination levels of facilities.

2.2.1.4 Need for Characterization of Underground Storage Tanks - Mixed wastes stored in underground storage tanks (single-shelled storage tanks (SSTS)).

2.2.1.5 Need for Better Analytical Procedures for Some Radionucliodes and Complex Organic Mixtures - Site characterization $\rightarrow$ soil, water, geo-phase samples, waste samples.

2.2.1.6 Need for Remote, In Situ, or Other Onsite Methods for Local Characterization of Contaminants - Subsurface contamination $\rightarrow$ buried concentrated waste forms (ex. tanks, trenches) dispersed contaminants in soil and water. Real-time monitoring of ambient volatile organics and toxic metals.

2.2.1.7 Need for Understanding Contaminant Distribution and Behavior in Subsurface Environment - Develop ways to optimize characterization of a given site; Develop sufficient understanding of subsurface processes; Basis for measuring and demonstrating that remediation measures are effective.

Table A.3 DOE Problem Set vs Problem Element

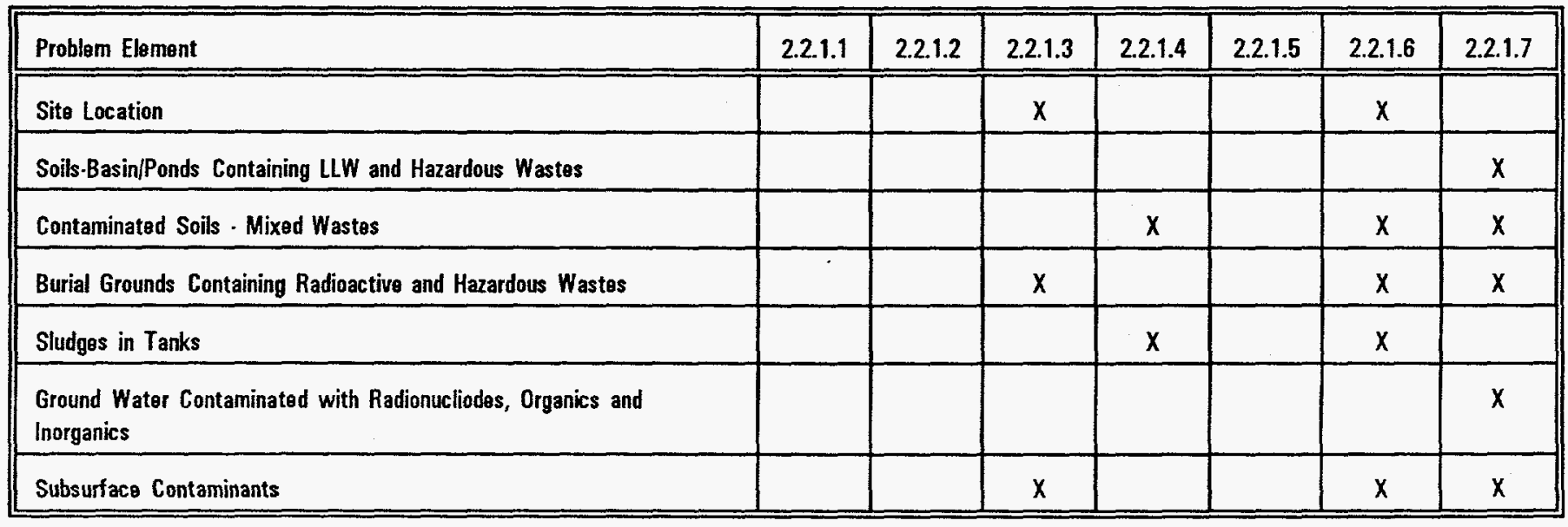


Table 1.4 Problem Elements vs Information Elements

\begin{tabular}{|c|c|c|c|c|c|c|c|}
\hline \multirow[b]{2}{*}{ Information Elaments } & \multicolumn{7}{|c|}{ Problem Elements } \\
\hline & $\begin{array}{c}\text { Site } \\
\text { Locations }\end{array}$ & $\begin{array}{l}\text { Soils-Basins/ } \\
\text { Ponds } \\
\text { Containing LLW } \\
\text { \& Hazardous } \\
\text { Wastes }\end{array}$ & $\begin{array}{l}\text { Contaminated } \\
\text { Soils - } \\
\text { Mixed Wastes }\end{array}$ & $\begin{array}{l}\text { Burial Grounds } \\
\text { Containing } \\
\text { Radioactive \& } \\
\text { Hazardous } \\
\text { Wastes }\end{array}$ & $\begin{array}{l}\text { Sludges in } \\
\text { Tanks }\end{array}$ & $\begin{array}{l}\text { Ground Water } \\
\text { Contaminated } \\
\text { w/Radionucliodes } \\
\text { Organics and } \\
\text { Inorganics }\end{array}$ & $\begin{array}{l}\text { Subsurface } \\
\text { Contaminants }\end{array}$ \\
\hline Location of Tanks & $X$ & & & $X$ & $x$ & & $x$ \\
\hline Characterization of Tanks & & & & $x$ & $X$ & & $x$ \\
\hline 3-0 Mapping of Tanks & & & & & $X$ & & $X$ \\
\hline $\begin{array}{l}\text { Identify Concentrated Wastes in } \\
\text { Trenches }\end{array}$ & & & $X$ & $\mathrm{X}$ & & & $x$ \\
\hline Locate Contaminants in Ground Water & & $X$ & & $X$ & & $X$ & $X$ \\
\hline $\begin{array}{l}\text { Track Migration of Contaminants in } \\
\text { Soils }\end{array}$ & & $X$ & $X$ & $X$ & & $X$ & $X$ \\
\hline Characterize Soils I & & & $X$ & & & & $X$ \\
\hline Location of Berms, Fences, LOCs & $X$ & $X$ & & $X$ & & & $X$ \\
\hline Detect/ID Cultural Litter, Scrap & $X$ & & & $x$ & & & $X$ \\
\hline
\end{tabular}


Table A.5 Information Elements vs Target Observables

\begin{tabular}{|c|c|c|c|c|c|c|c|c|c|}
\hline Target Observables & $\begin{array}{l}\text { Location } \\
\text { of } \\
\text { Tanks }\end{array}$ & $\begin{array}{c}\text { Characterization } \\
\text { of Tanks }\end{array}$ & $\begin{array}{l}\text { 3-D Map } \\
\text { of Tanks }\end{array}$ & $\begin{array}{c}\text { Identify } \\
\text { Concentrated } \\
\text { Waste in } \\
\text { Trenches } \\
\end{array}$ & $\begin{array}{c}\text { Locate } \\
\text { Contaminants } \\
\text { in Ground } \\
\text { Water }\end{array}$ & $\begin{array}{c}\text { Track } \\
\text { Migration of } \\
\text { Contaminants } \\
\text { in Soils } \\
\end{array}$ & $\begin{array}{l}\text { Characterize } \\
\text { Soils }\end{array}$ & $\begin{array}{c}\text { Locate } \\
\text { Berms! } \\
\text { Fences/ } \\
\text { LOC } \\
\end{array}$ & $\begin{array}{c}\text { Detect//D } \\
\text { Cultural } \\
\text { Litter/Scrap }\end{array}$ \\
\hline Vegotation Stress/Vigor & $\mathrm{x}$ & & & $x$ & $x$ & $x$ & $x$ & $x$ & \\
\hline Soil Moisture Content Changes/Drainage & $x$ & & & $x$ & $x$ & $x$ & $x$ & $x$ & \\
\hline Soil Compaction Changes & $x$ & & & & $x$ & $x$ & $x$ & $x$ & $x$ \\
\hline Desert "Varnish" Disruption & $x$ & $x$ & & $x$ & $x$ & $x$ & $x$ & $x$ & $x$ \\
\hline Anomalous Vegetation Growth & $x$ & $x$ & & $x$ & $x$ & $x$ & $x$ & $x$ & $x$ \\
\hline Exo/Endothermic Heat Sources/Sinks & $x$ & $x$ & & $x$ & $x$ & $x$ & $x$ & & \\
\hline Tank/Soil Thermal Indicators & $x$ & $x$ & & & & $x$ & & & \\
\hline Local Surface Contour Indicators & $x$ & $x$ & & $x$ & $x$ & & & & \\
\hline Soil/Mineral Discoloration & $x$ & $x$ & & $x$ & $x$ & $x$ & $x$ & & $x$ \\
\hline Tank/Cavity 3-D Profile & & & $x$ & & & & & $x$ & \\
\hline Principle Chemical Constituents & & & & & & & $x$ & & \\
\hline Fences/Posts/Footings & & & & & & & & $x$ & \\
\hline Ambient/Diurnal Thermal Changes & $x$ & & & & & & & $x$ & $x$ \\
\hline Surface/Subsurface Metals & & & & & & & & & $x$ \\
\hline
\end{tabular}


A.6.1 Example of One Problem Element Derived from DOE Problem Sets

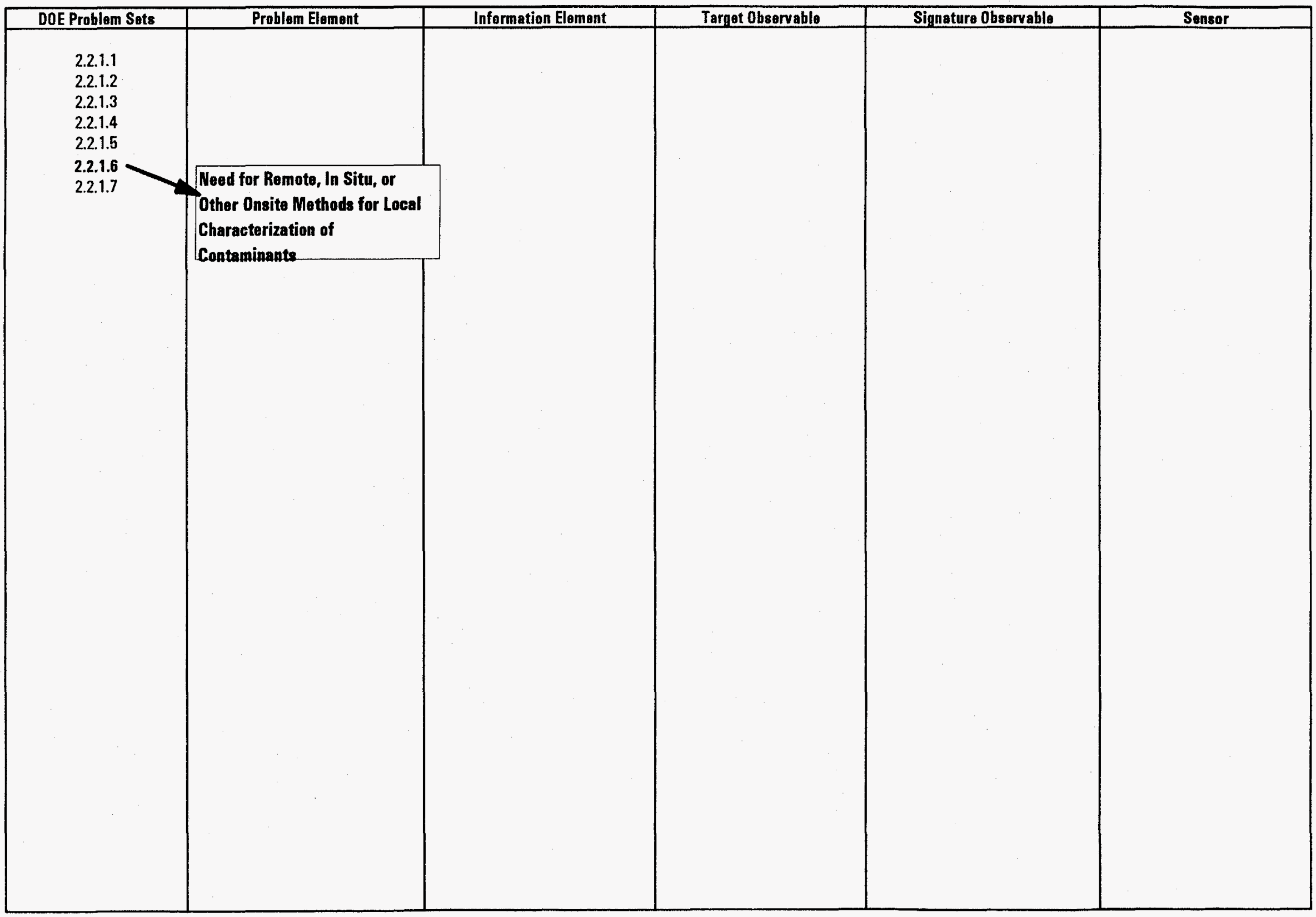


A.6.2 Example of One Problem Element Derived from DOE Problem Sets

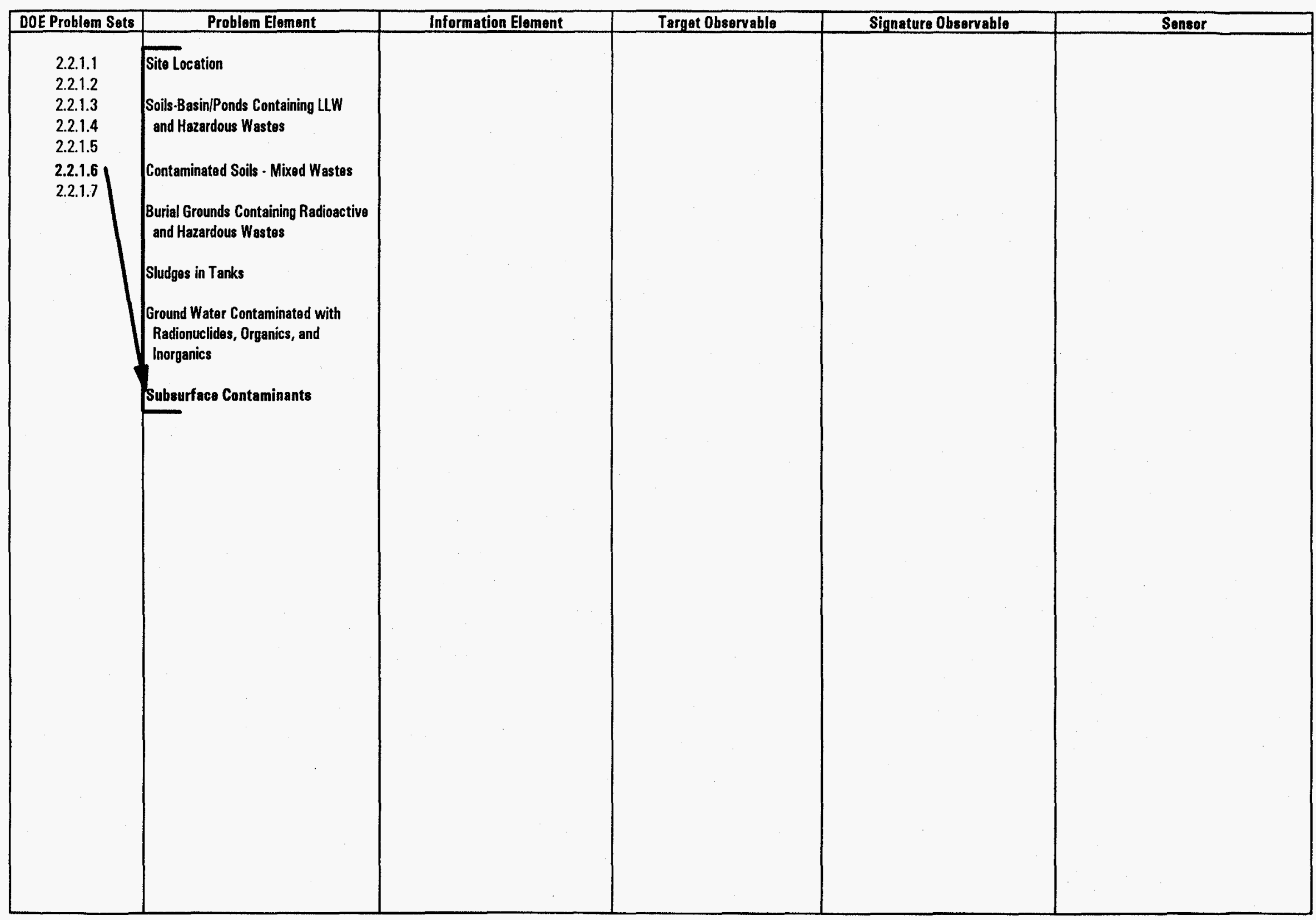


A.7 Example of Information Elements for One Problem Element Derived from DOE Problem Sets

\begin{tabular}{|c|c|c|c|c|c|}
\hline DOE Problem Sots & Problem Eloment & Information Element & Target Observable & Signature Obsorvable & Sonsar \\
\hline $\begin{array}{l}2.2 .1 .1 \\
2.2 .1 .2 \\
2.2 .1 .3 \\
2.2 .1 .4 \\
2.2 .1 .5 \\
2.2 .1 .6 \\
2.2 .1 .7\end{array}$ & $\begin{array}{l}\text { Site Location } \\
\text { Soils-Basin/Ponds Containing LWW } \\
\text { and Hazardous Wastes } \\
\text { Contaminated Soils - Mixed Wastes } \\
\text { Burial Grounds Containing Radioactive } \\
\text { and Hazardous Wastes } \\
\text { Sludges in Tanks } \\
\text { Ground Water Contaminatad with } \\
\text { Radionuclides, Organics, and } \\
\text { Inorganics } \\
\text { Suhsurface Contaminants }\end{array}$ & $\begin{array}{l} \\
\\
\text { Location of Tanks } \\
\text { Characterization of Tanks } \\
\text { 3.0 Mapping of Tanks } \\
\text { Identify Concentratod Wasta in } \\
\text { Trenches } \\
\text { Locate Contaminants in Groundwater } \\
\text { Track Migration of Contaminants in } \\
\text { Soils } \\
\text { Characterize Soils } \\
\text { Location of Borms/Fences/LOCs } \\
\text { Detect//d. Cuitural Litter/Scrap }\end{array}$ & & & \\
\hline
\end{tabular}


A.8.1 Example of Target Observables and Signature Observables for One Information Element Associated with One Problem Element Derived from DOE Problem Sets

\begin{tabular}{|c|c|c|c|c|c|}
\hline DOE Problem Sots & Prablem Element & Information Element & Target Observable & Signature Observable & Senser \\
\hline $\begin{array}{l}2.2 .1 .1 \\
2.2 .1 .2 \\
2.2 .1 .3 \\
2.2 .1 .4 \\
2.2 .1 .5 \\
2.2 .1 .6 \\
2.2 .1 .7\end{array}-$ & $\begin{array}{l}\text { Site Location } \\
\text { Soils.Basin/Ponds Containing LLW } \\
\text { and Hazardous Wastes } \\
\text { Contaminated Soils - Mixed Wastes } \\
\text { Burial Grounds Containing Radioactive } \\
\text { and Hazardous Wastes } \\
\text { Sludges in Tanks } \\
\text { Ground Water Contaminated with } \\
\text { Radionuclides, Organics, and } \\
\text { Inorganics } \\
\text { Subsurface Contaminants }\end{array}$ & 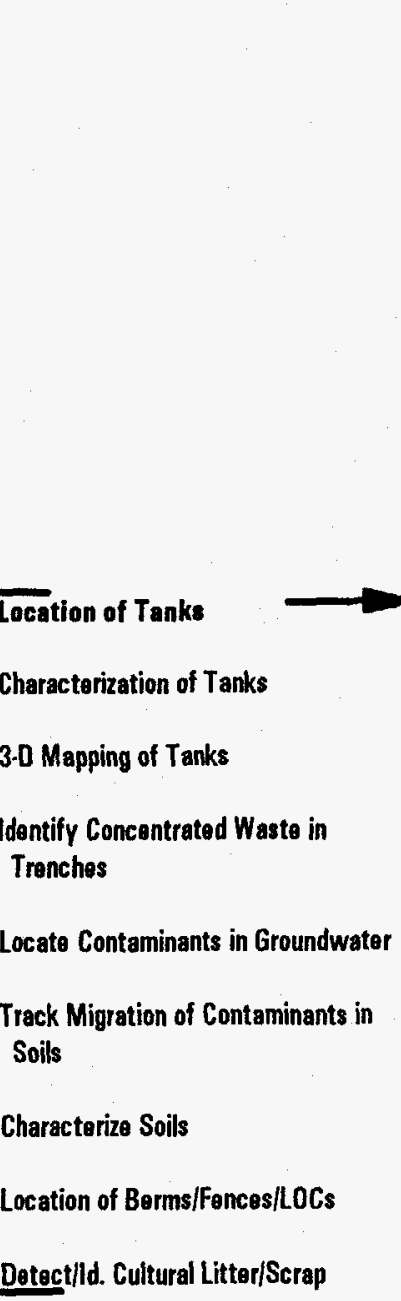 & $\begin{array}{l}\text { Degetation Stress } \\
\text { Soil Maisture Content Changes } \\
\text { Soil Compaction Changes } \\
\text { Anomalous Vegetative Growth } \\
\text { Exothermic Heat Sources } \\
\text { Tank/Soil Thermal Indicators } \\
\text { Local Surface Contour Indicators } \\
\end{array}$ & & \\
\hline
\end{tabular}


A.8.2 Example of Target Observables, Signature Observables, and Sensors for One

Information Element Associated with One Problem Element Derived from DOE Problem Sets

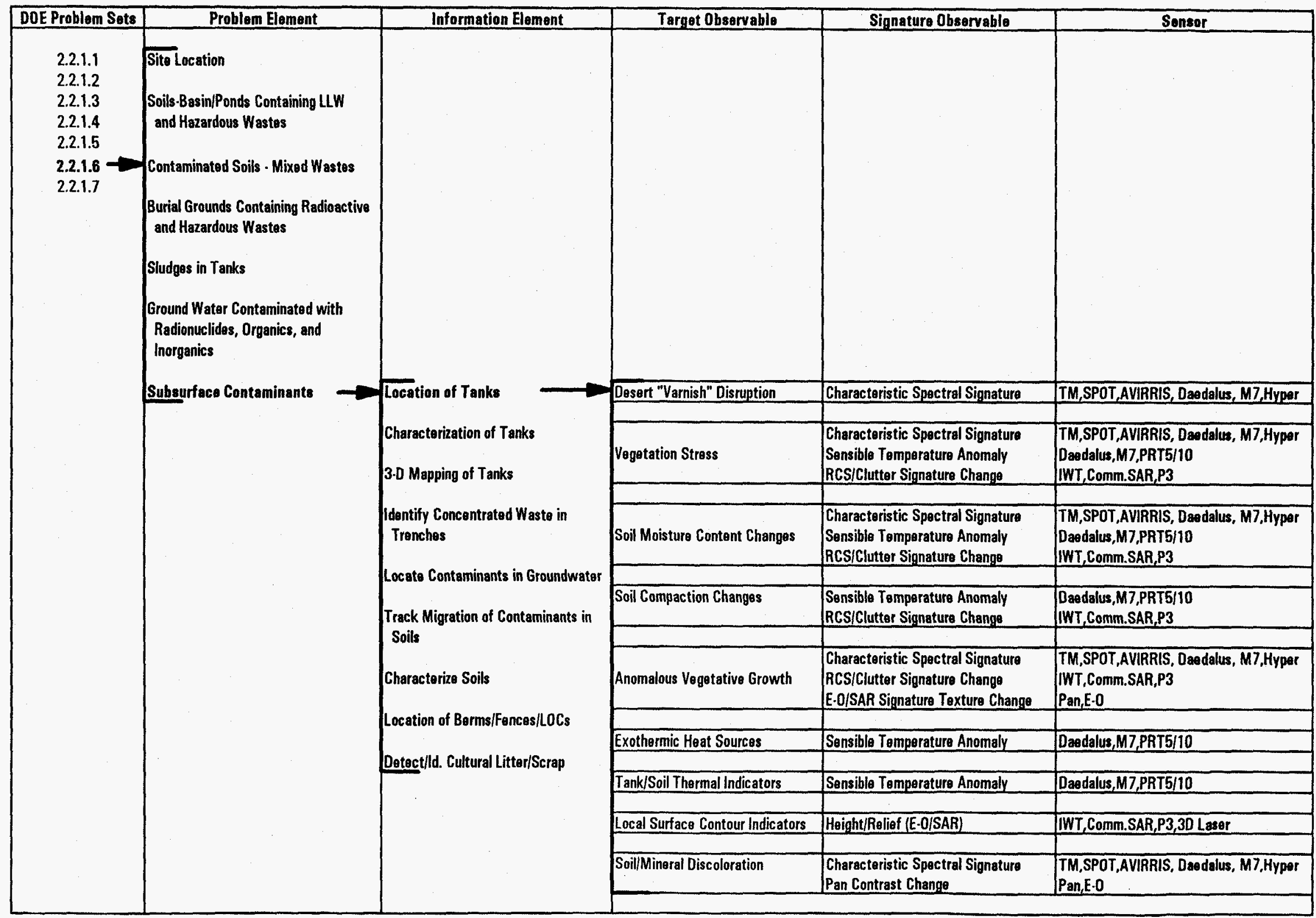


A.9.1.1 Target Observables, Signature Observables, and potential Sensors Associated with Information Elements Derived from "Site Location" Problem Element

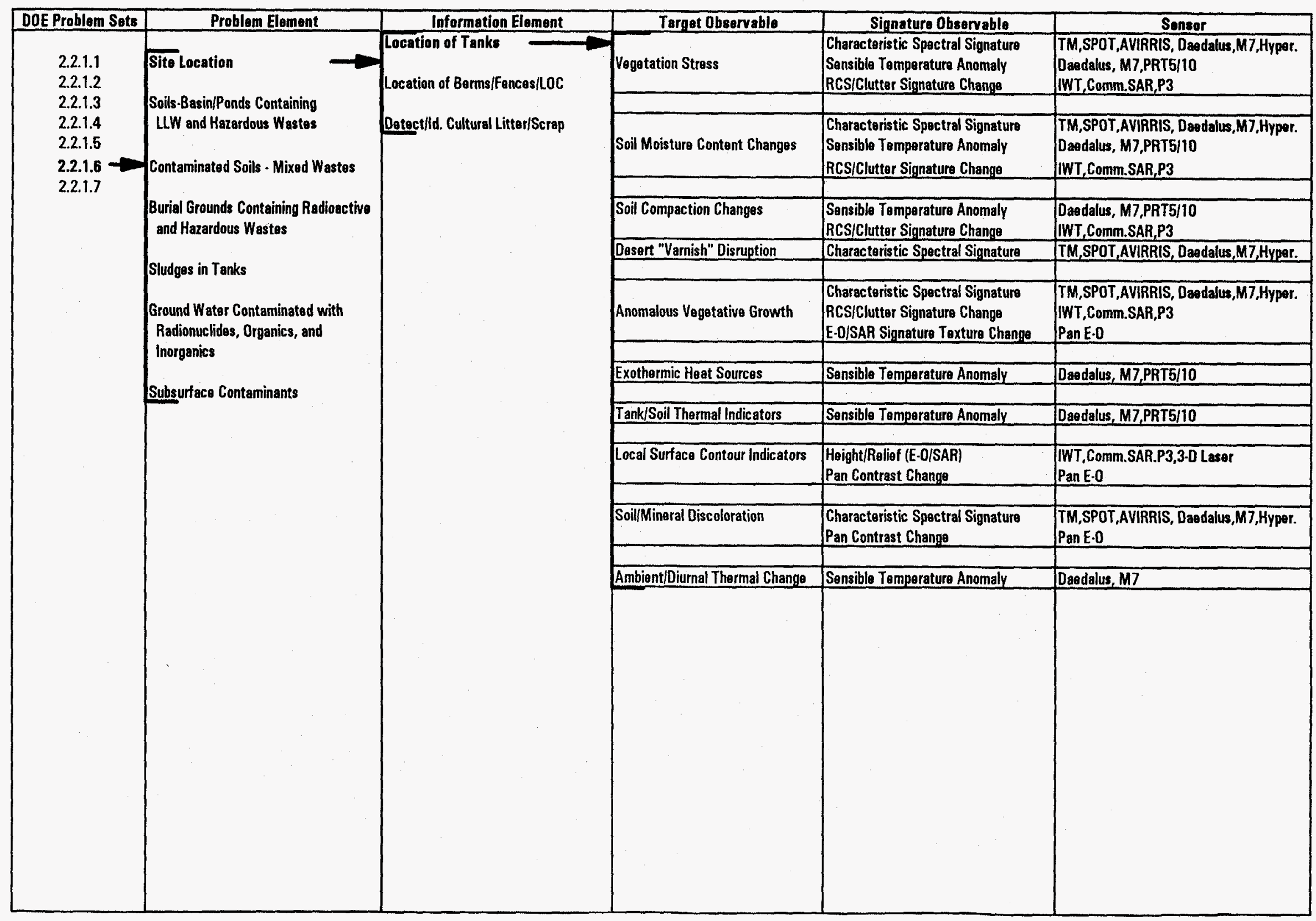


A.9.1.2 Target Observables, Signature Observables, and potential Sensors Associated with Information Elements Derived from "Site Location" Problem Element

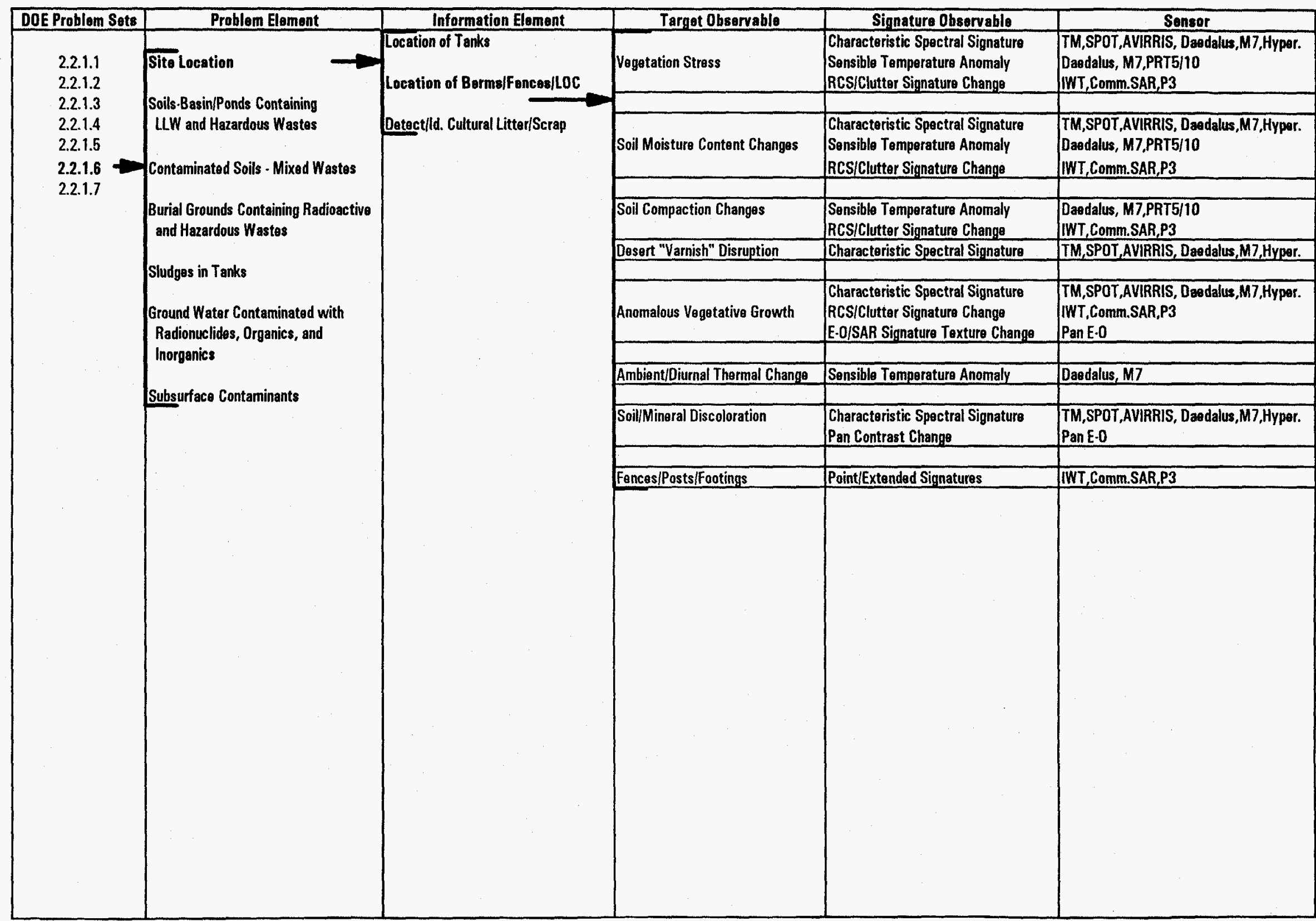


A.9.1.3 Target Observables, Signature Observables, and potential Sensors Associated with Information Elements Derived from "Site Location" Problem Element

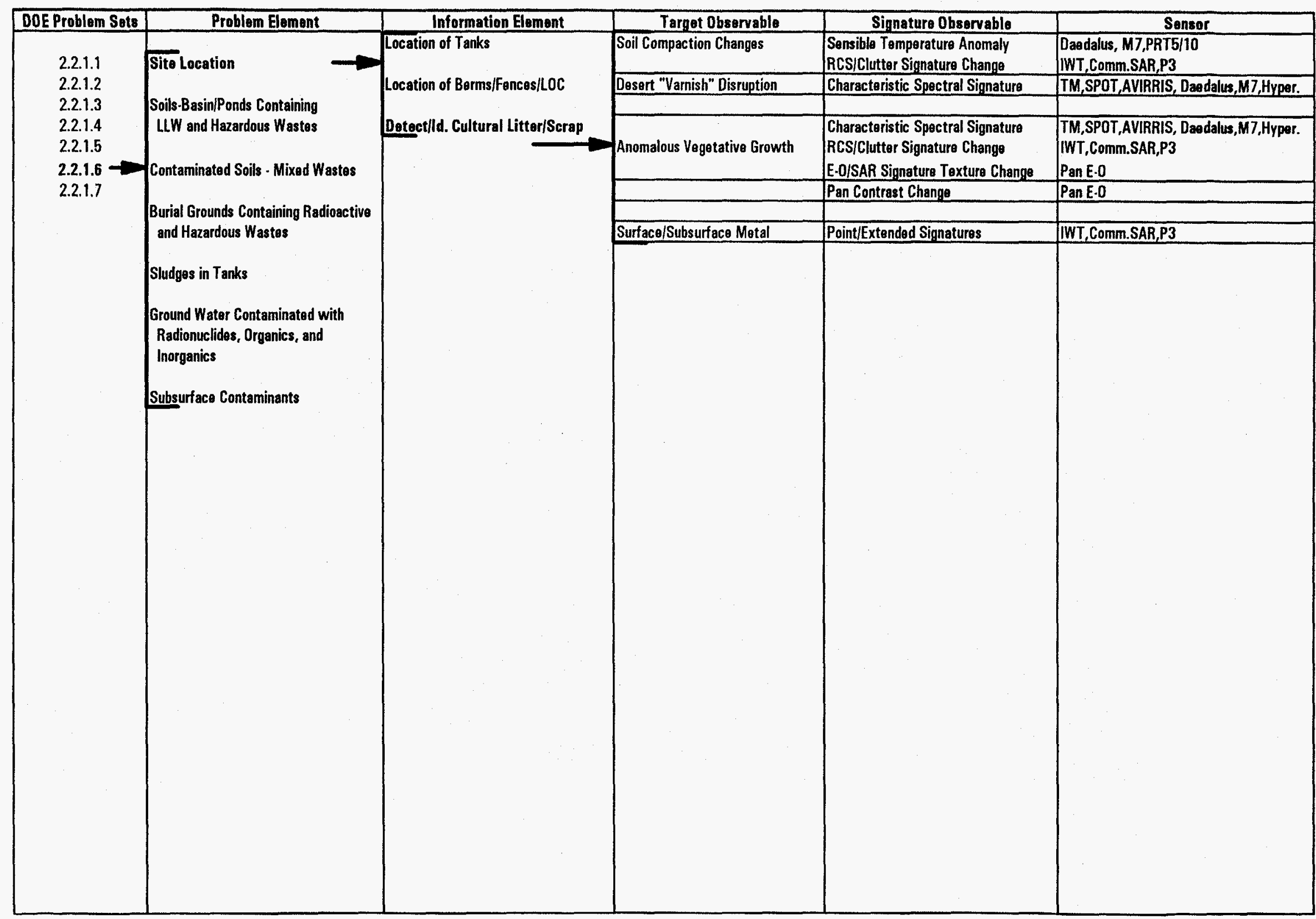


A.9.2.1 Target Observables, Signature 0bservables, and potential Sensors Associated with Information Elements Derived from "Soils.Basin/Ponds Containing Low Level Waste (LLW) and Hazardous Wastes" Problem Element

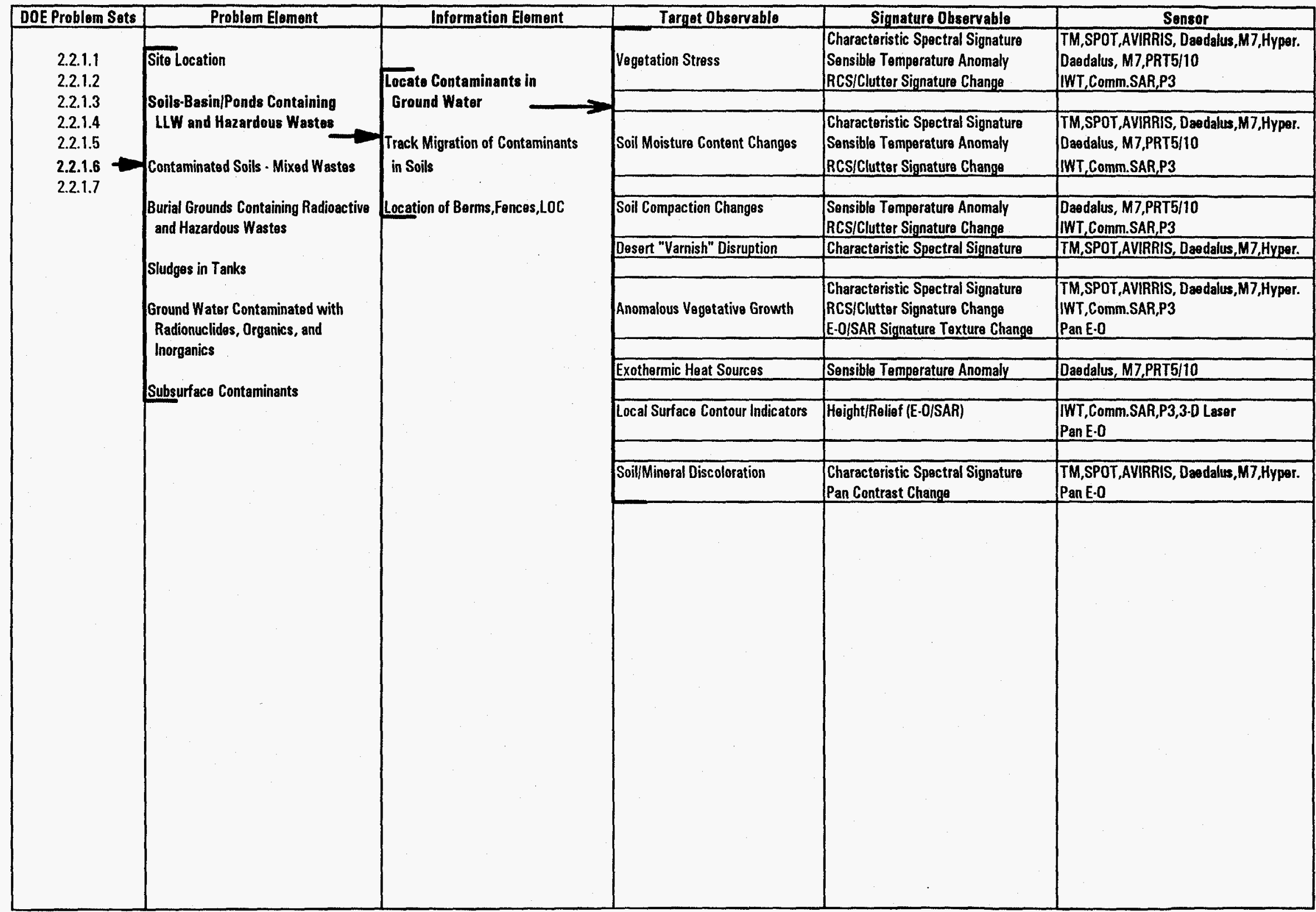


A.9.2.2 Target Observables, Signature Observables, and potential Sensors Associated with Information Elements Derived from "Soils-Basin/Ponds Containing Low Level Waste (LLW) and Hazardous Wastes" Problem Element

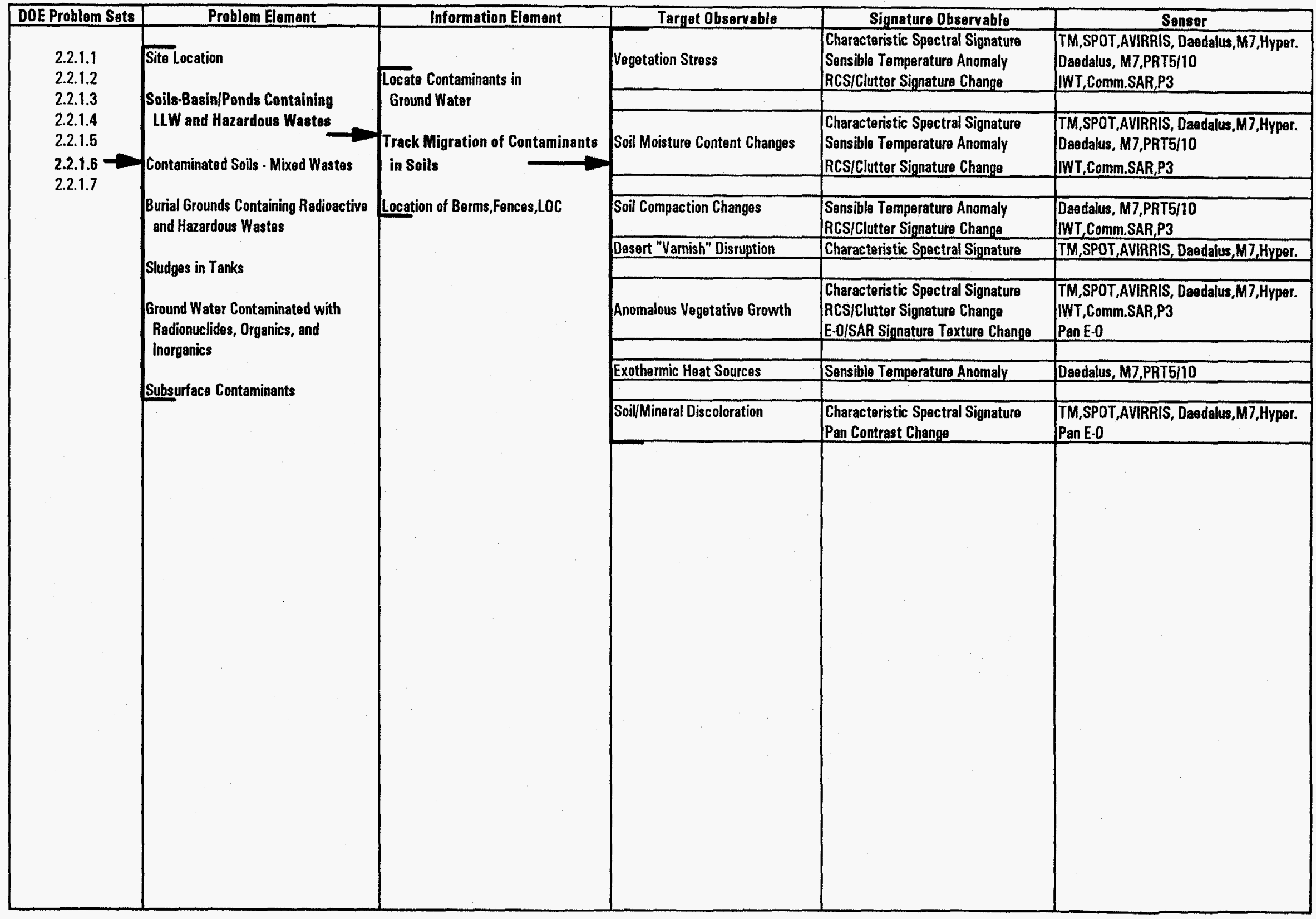


A.9.2.3 Target Observables, Signature Observables, and potential Sensors Associated with Information Elements Derived from "Soils-Basin/Ponds Containing Low Level Waste (LLW) and Hazardous Wastes" Problem Element

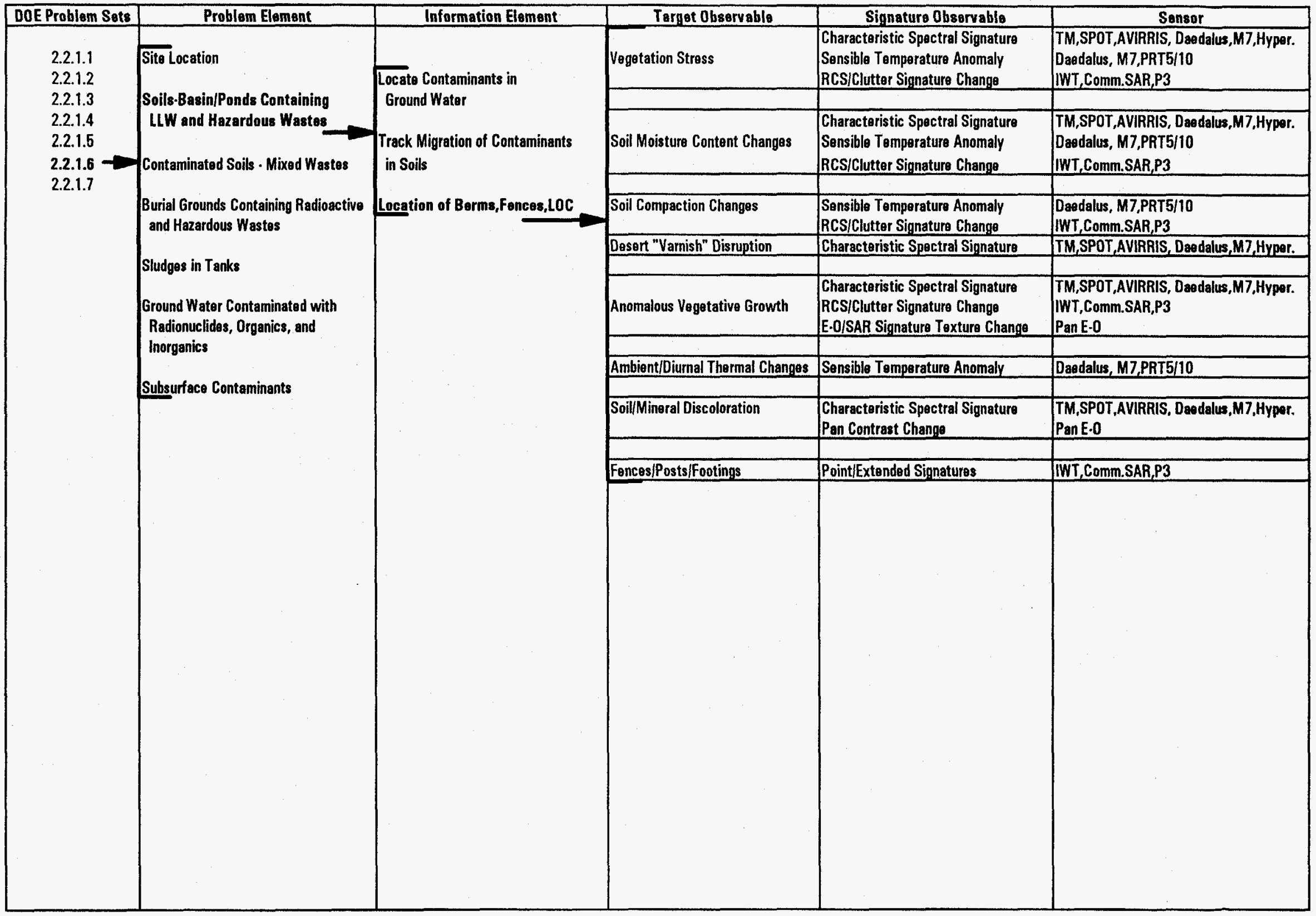


A.9.3.1 Target Observables, Signature Observables, and potential Sensors Associated with Information Elements Derived from "Contaminated Soils-Mixed Waste" Problem Element

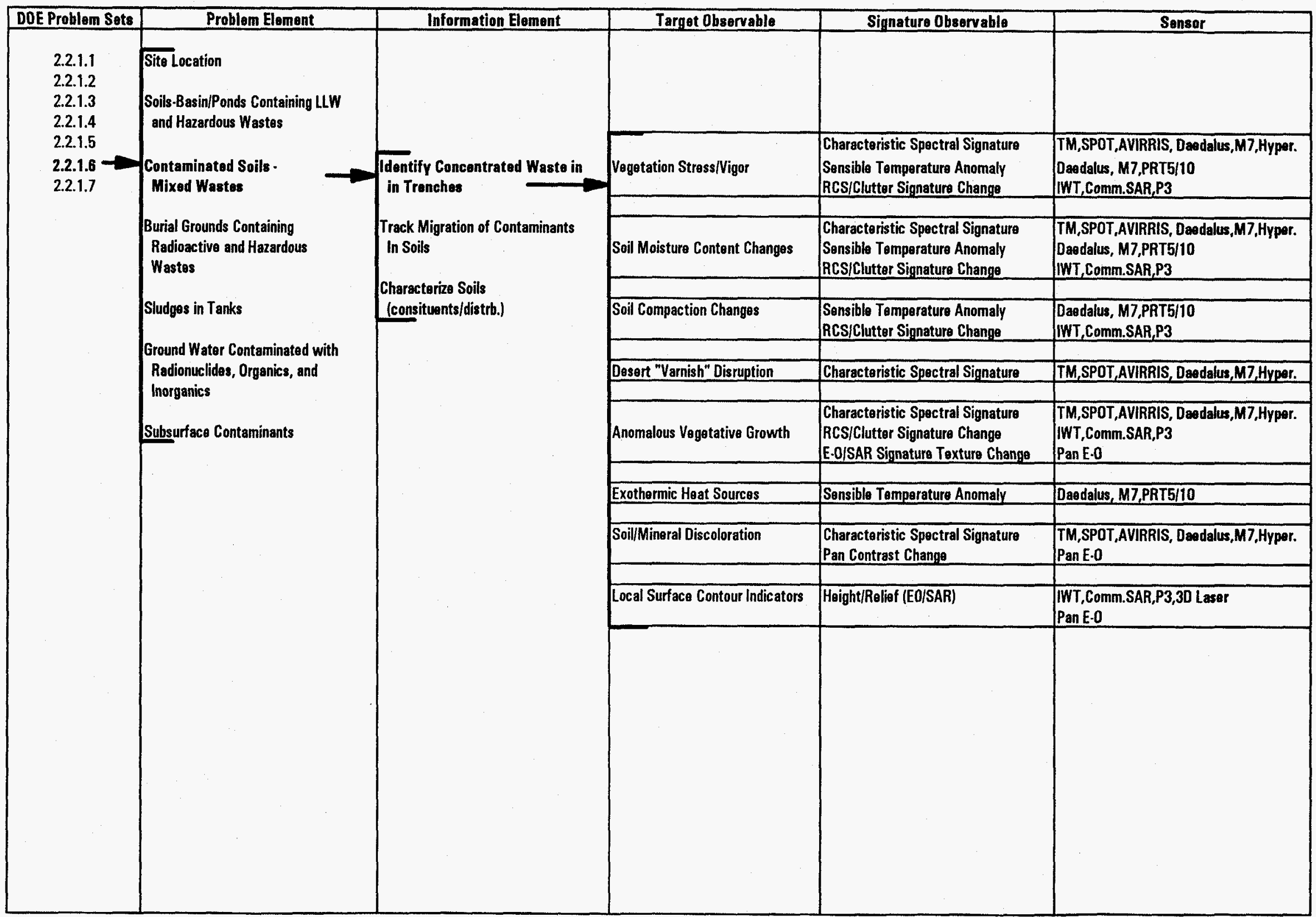


A.9.3.2 Target Observables, Signature Observables, and potential Sensors Associated with Information Elements Derived from "Contaminated Soils-Mixed Waste" Problem Element

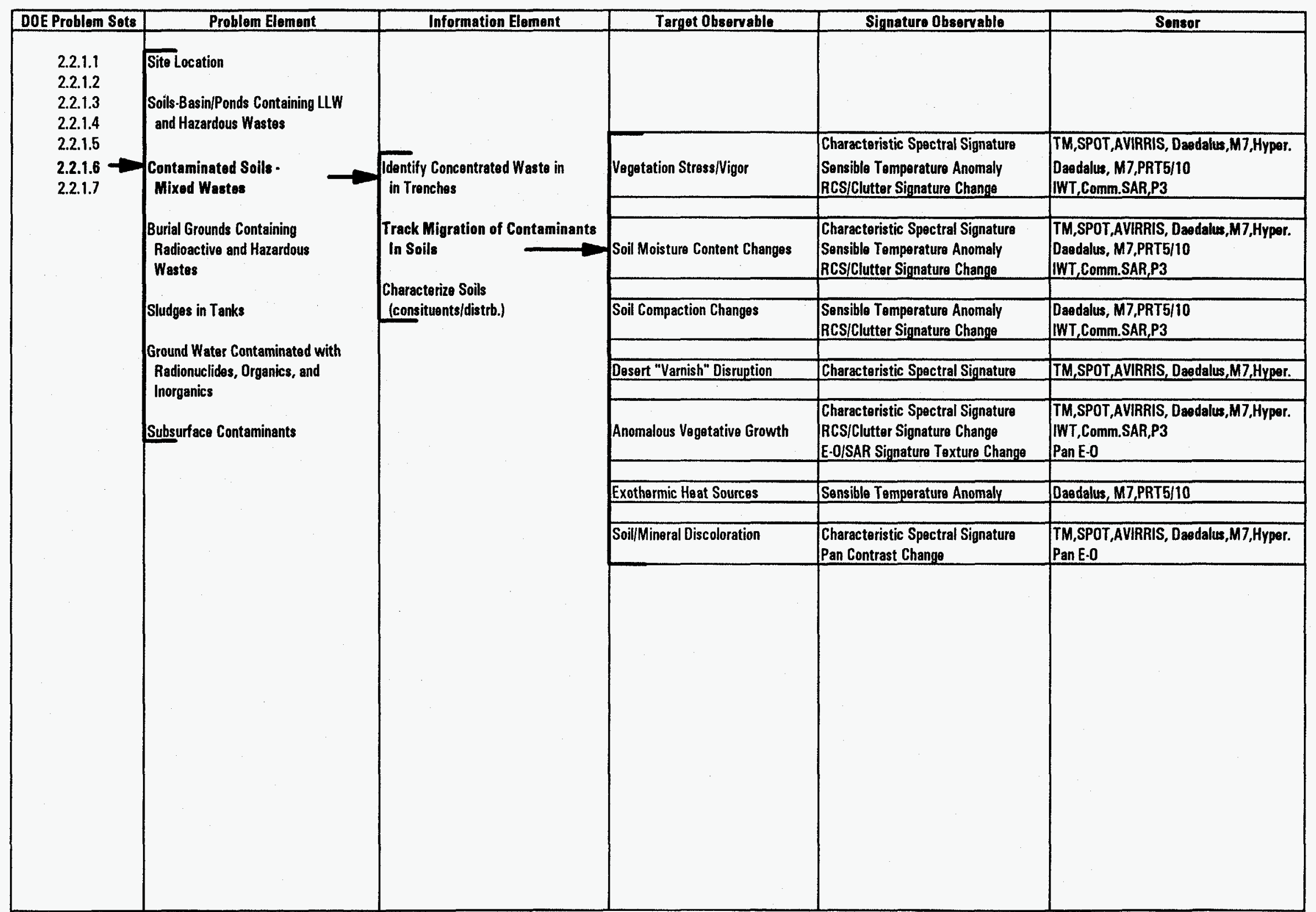


A.9.3.3 Target Observables, Signature Observables, and potential Sensors Associated with Information Elements Derived from "Contaminated Soils-Mixed Waste" Problem Element

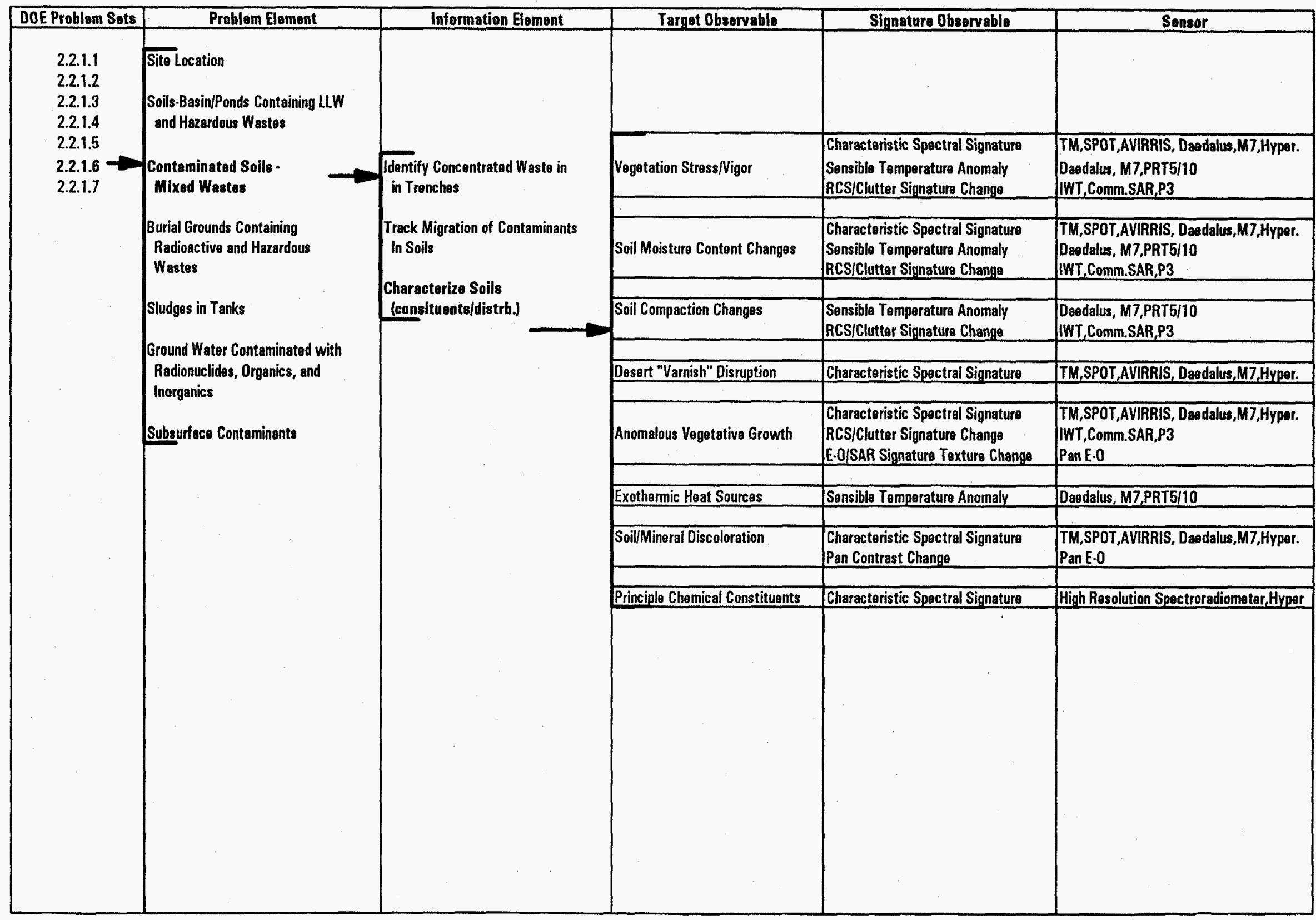


A.9.4.1 Target Observables, Signature Observables, and potential Sensors Associated with Information

Elements Derived from "Burial Grounds Containing Radioactive and Hazardous Wastes" Problem Element

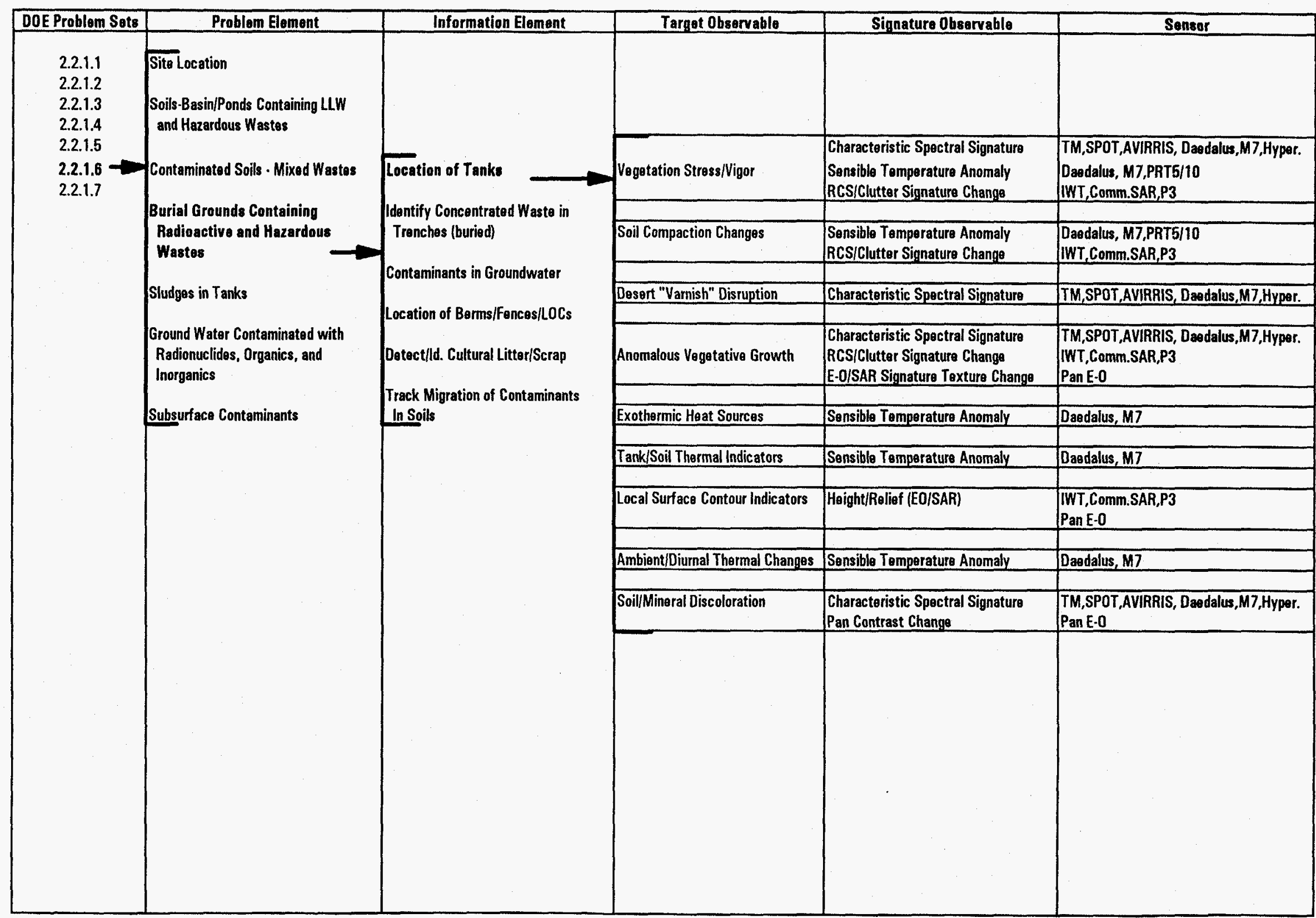


A.9.4.2 Target 0bservables, Signature Observables, and potential Sensors Associated with Information Elements Derived from "Burial Grounds Containing Radioactive and Hazardous Wastes" Problem Element

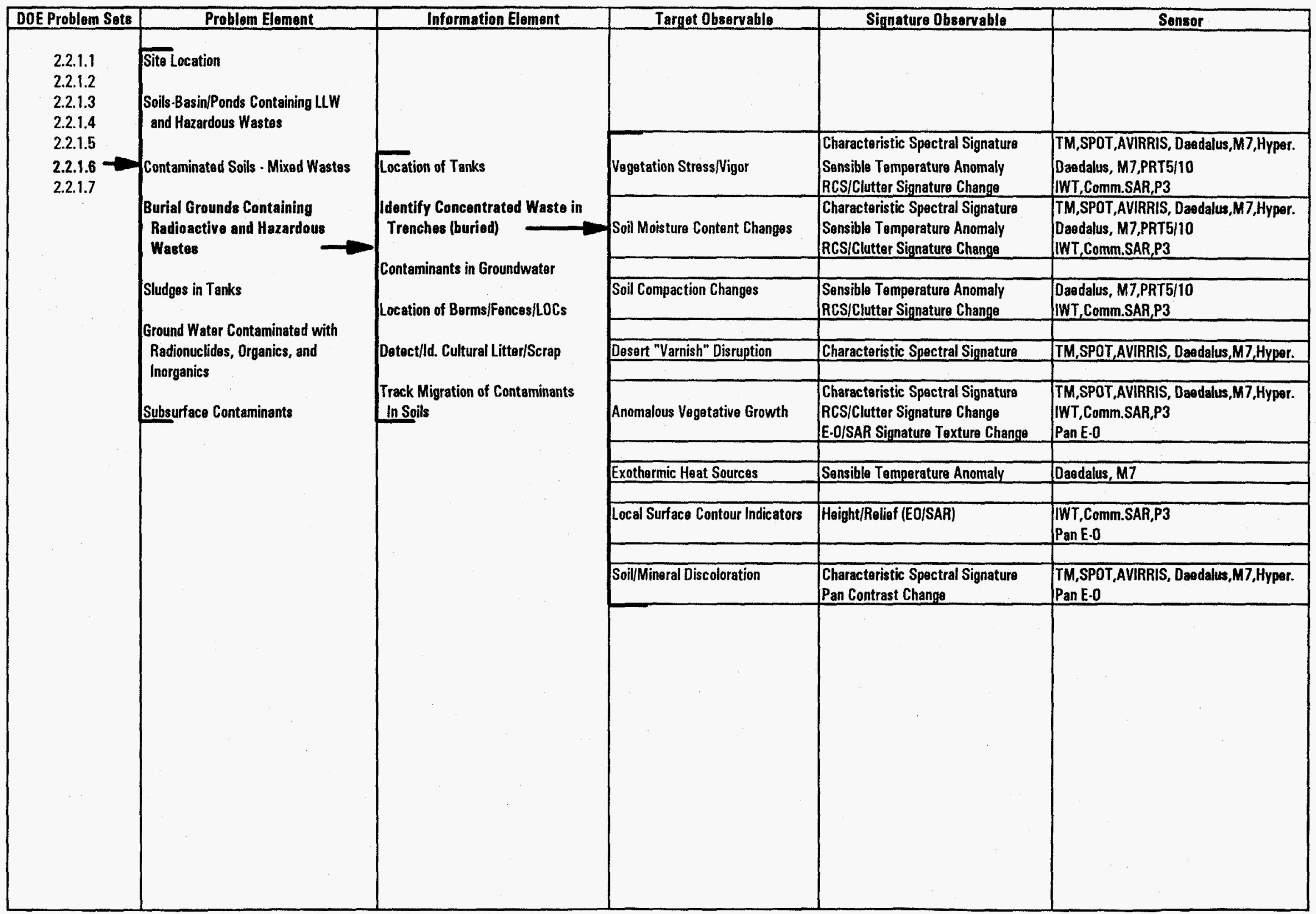


A.9.4.3 Target Observables, Signature Observables, and potential Sensors Associated with Information Elements Derived from "Burial Grounds Containing Radioactive and Hazardous Wastes" Problem Element

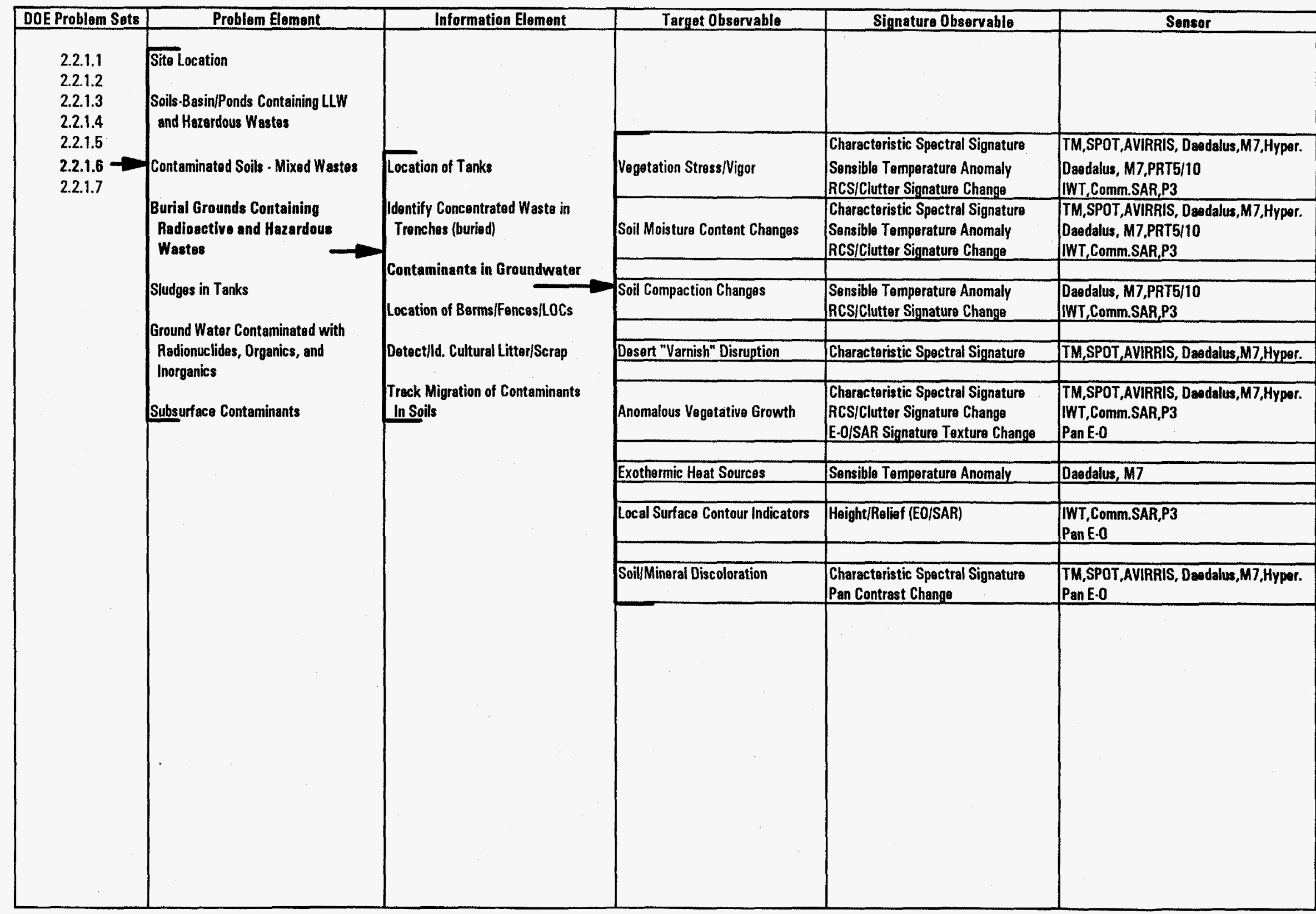


A.9.4.4 Target Observables, Signature Observables, and potential Sensors Associated with Information

Elements Derived from "Burial Grounds, Containing Radioactive and Hazardous Wastes" Problem Element

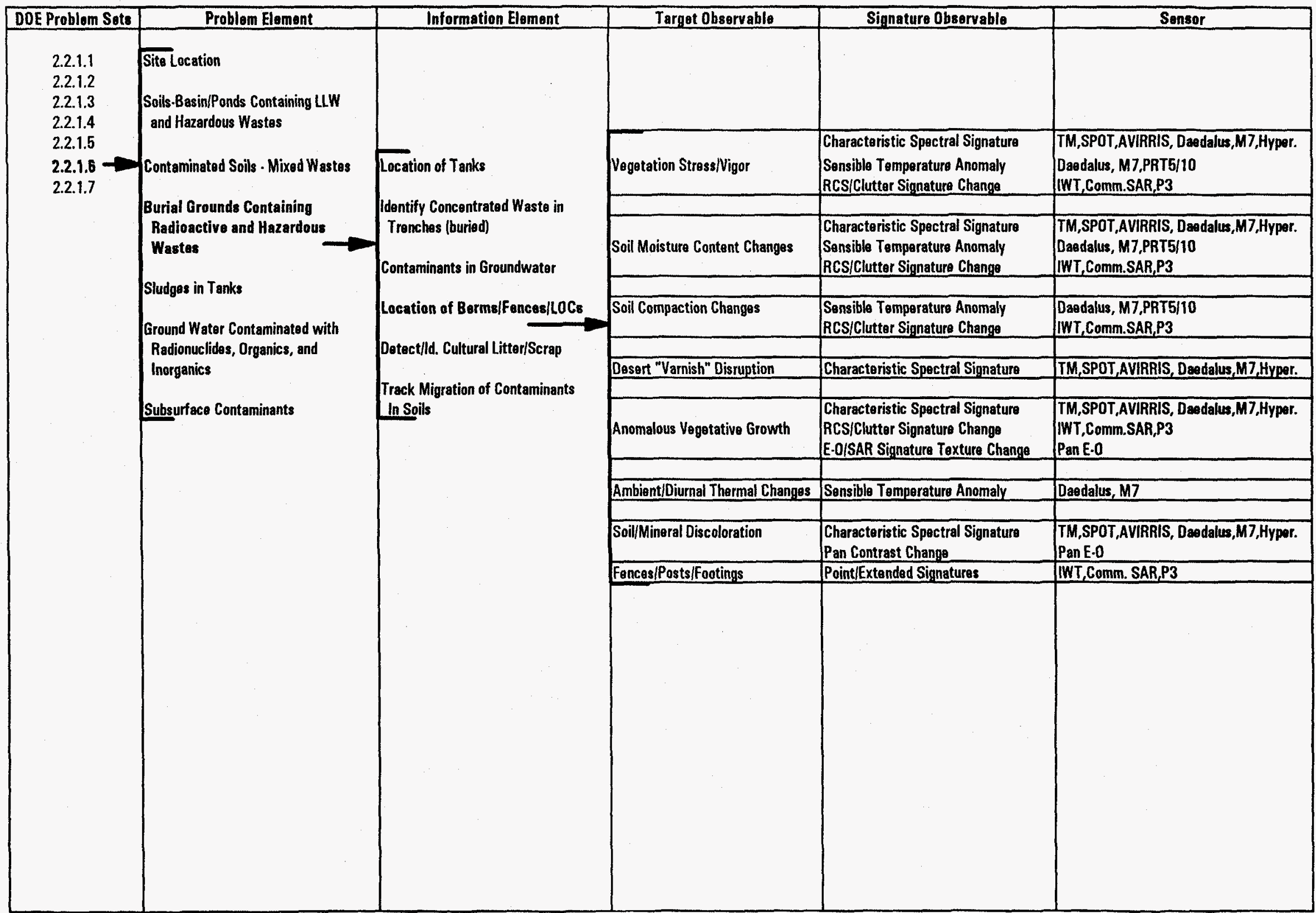


A.9.4.5 Target Observables, Signature Observables, and potential Sensors Associated with Information Elements Derived from "Burial Grounds Containing Radioactive and Hazardous Wastes" Problem Element

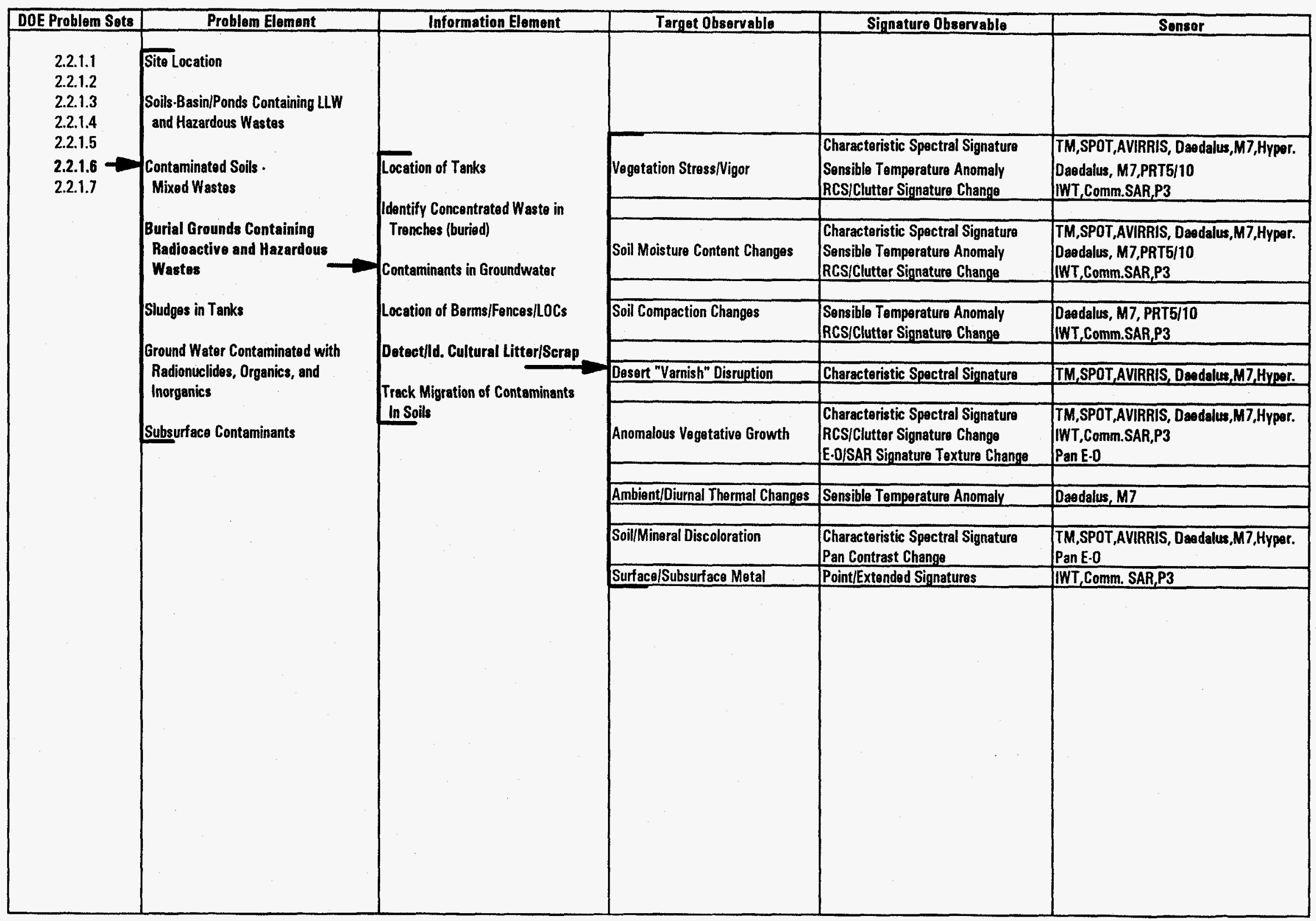


A.9.4.6 Target Observables, Signature Observables, and potential Sensors Associated with Information Elements Derived from "Burial Grounds Containing Radioactive and Hazardous Wastes" Problem Element

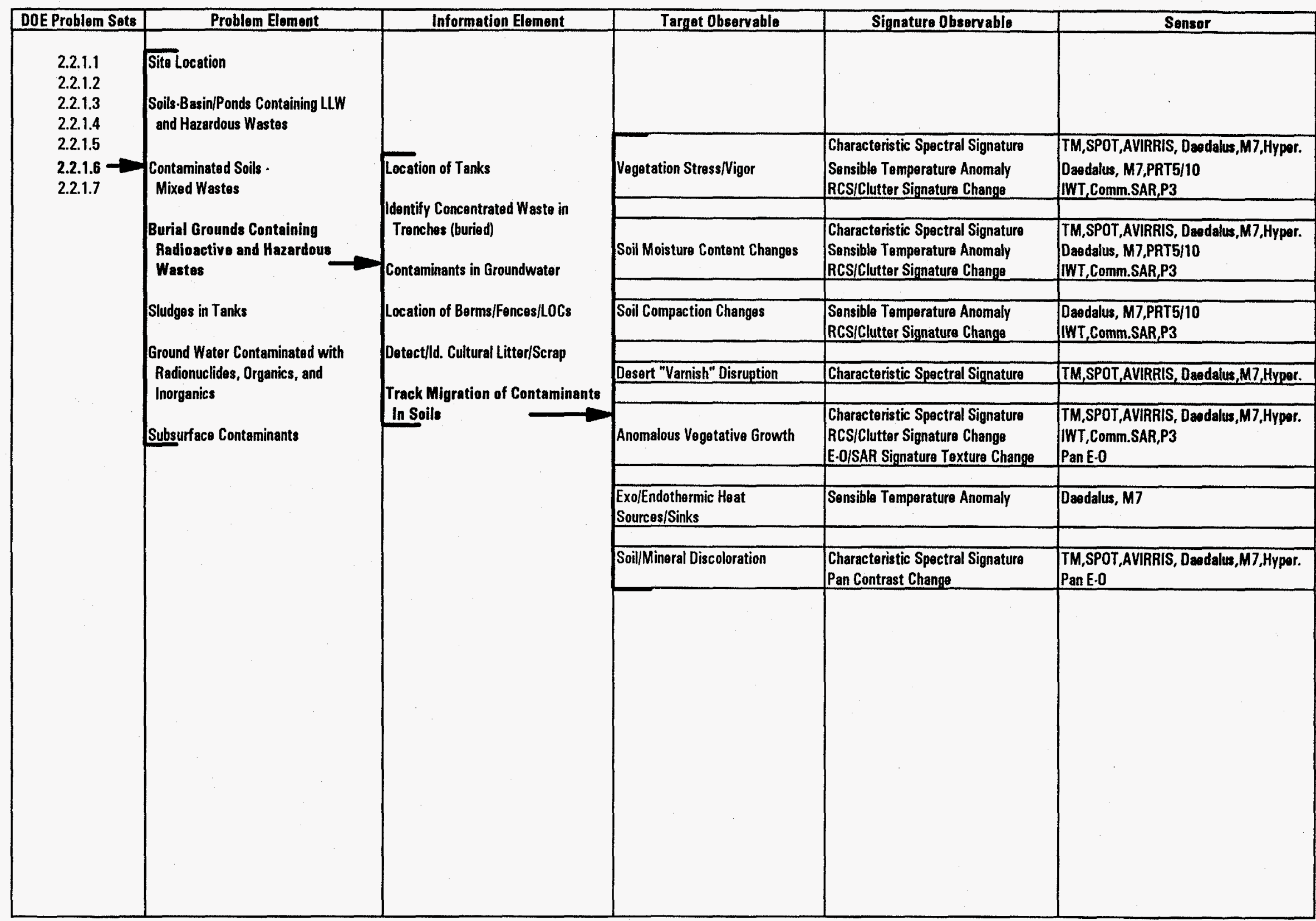


A.9.5.1 Target Observables, Signature Observables, and potential Sensors Associated with Information Elements Derived from "Sludges in Tanks" Problem Element

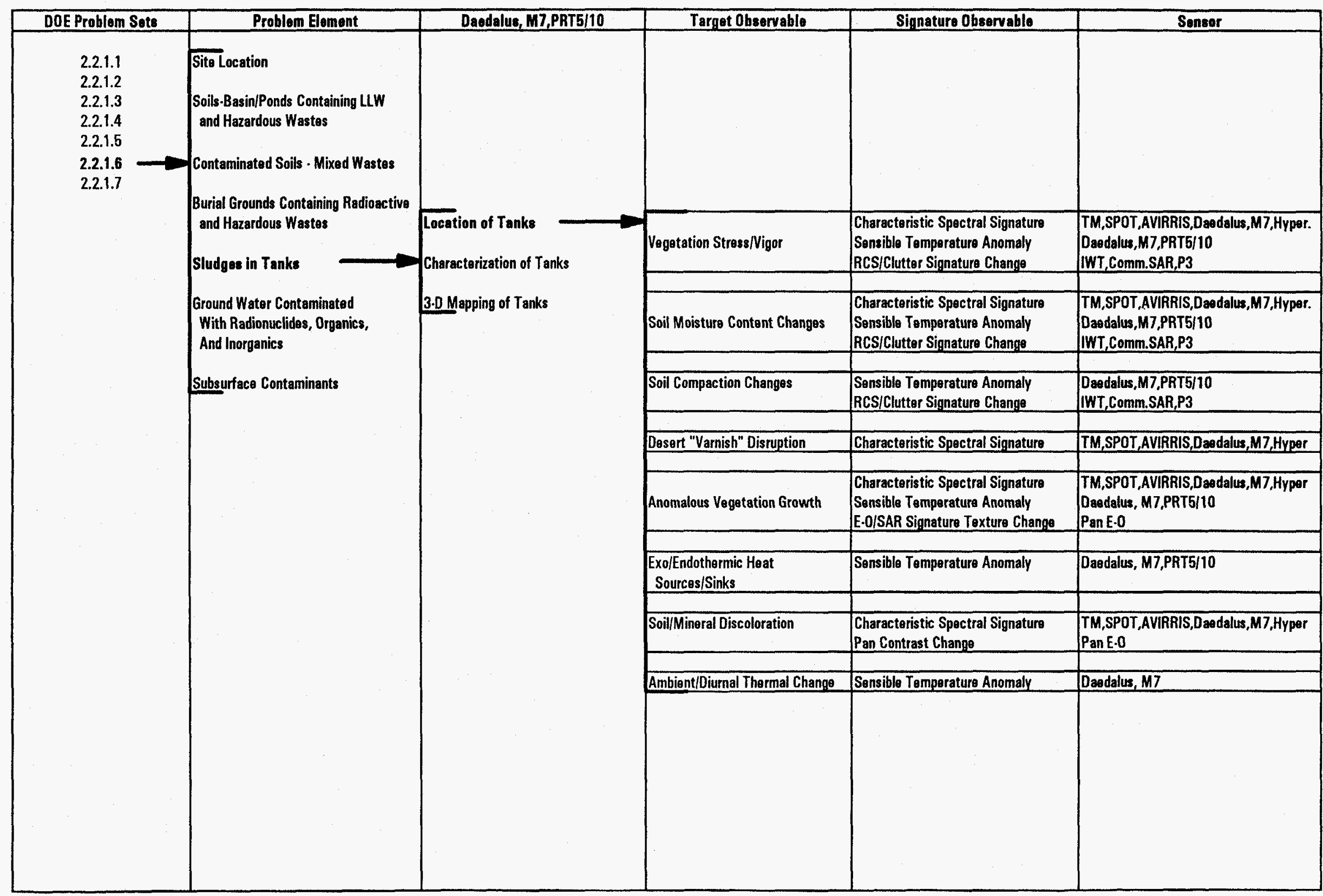


A.9.5.2 Target Observables, Signature Observables, and potential Sensors Associated with Information Elements Derived from "Sludges in Tanks" Problem Element

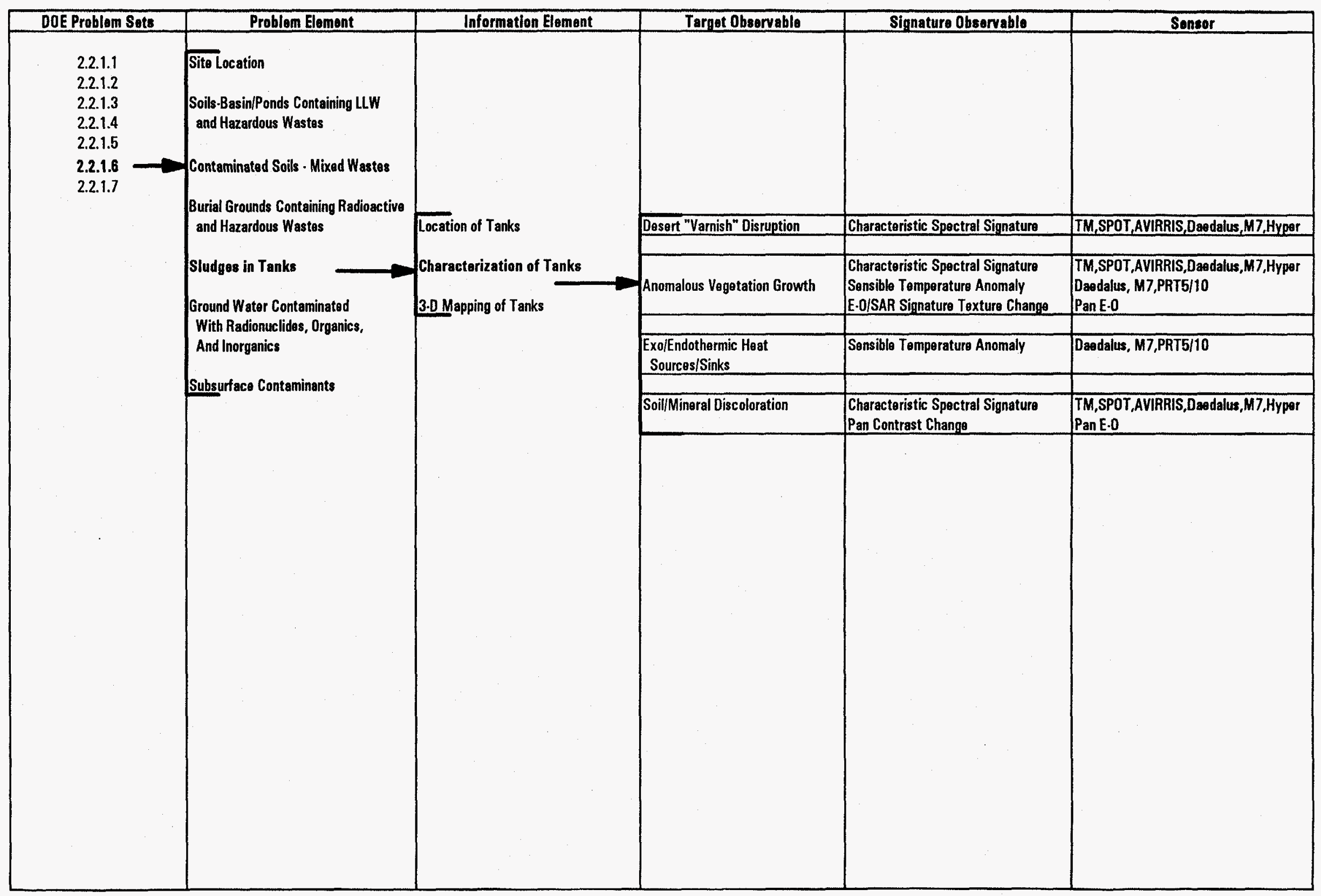


A.9.5.3 Target Observabes, Signature Observables, and potential Sensors Associated with Information Elements Derived from "Sludges in Tanks" Problem Element

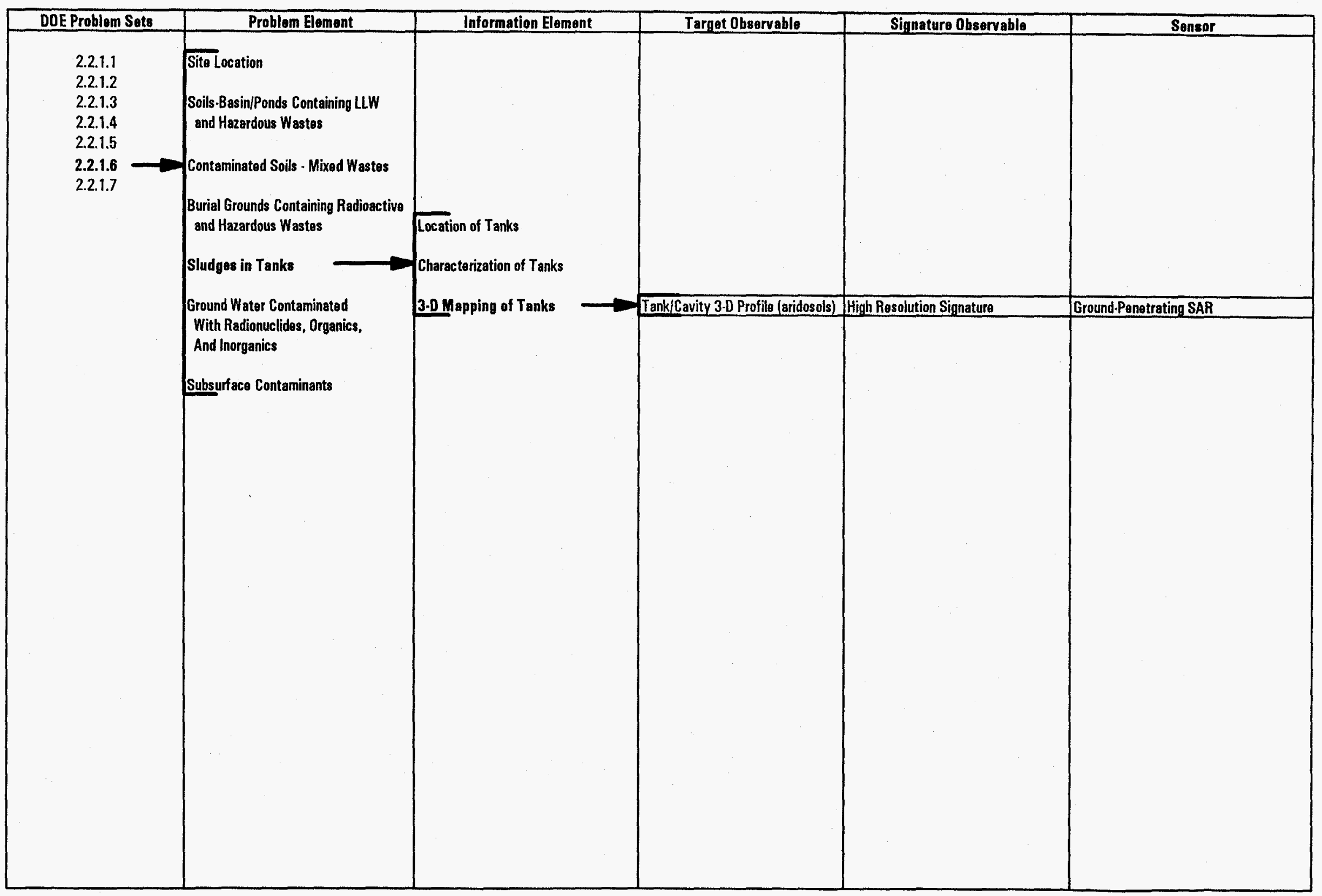


A.9.6.1 Target Observables, Signature Observables, and potential Sensors Associated with Information Elements Derived from "Ground Water Contaminated with Radionuclides, Organics, and Inorganics" Problem Element

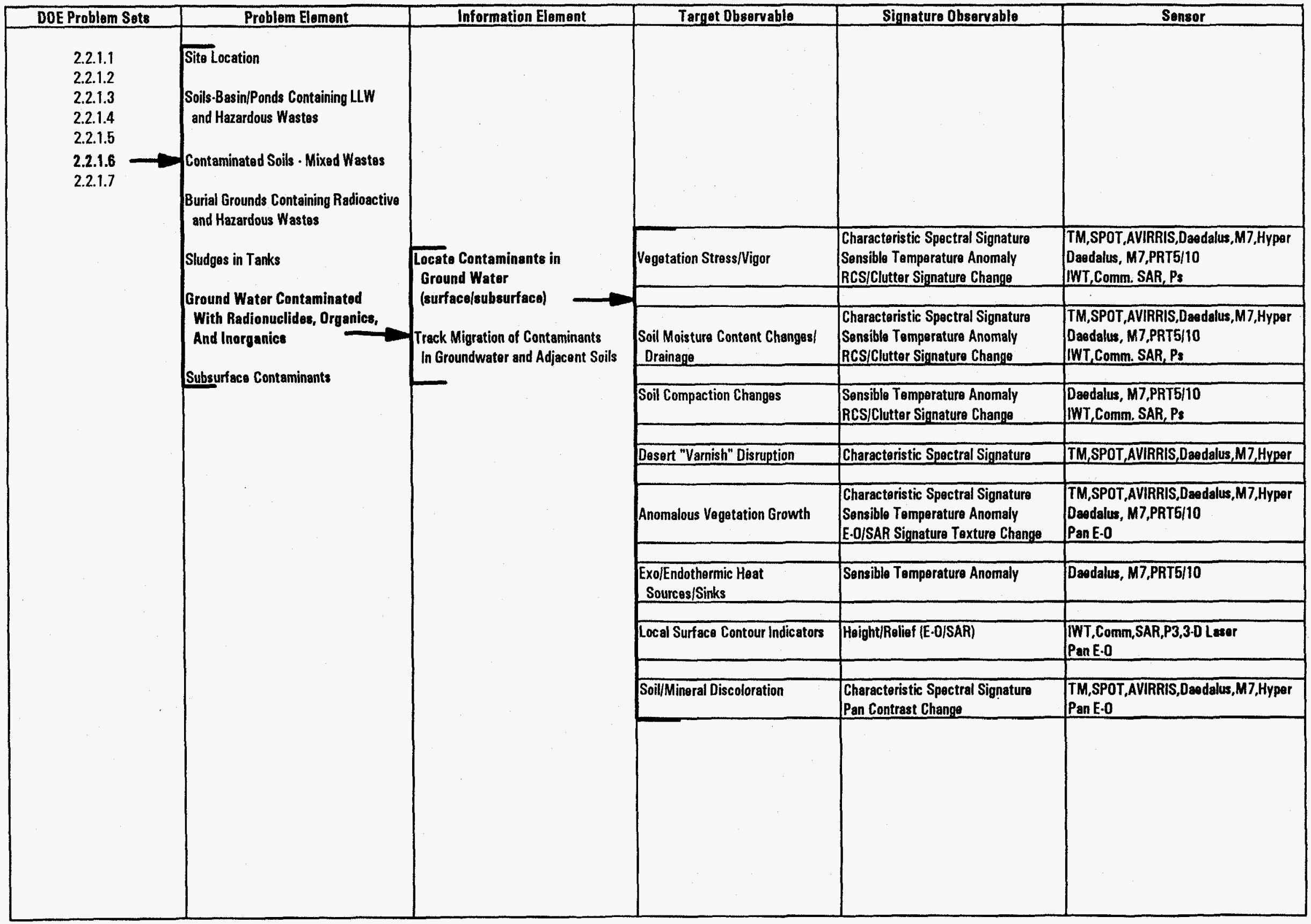


A.9.6.2 Target Observables, Signature Observables, and potential Sensors Associated with Information Elements Derived from "Ground Water Contaminated with Radionuclides, Organics, and Inorganics" Problem Element

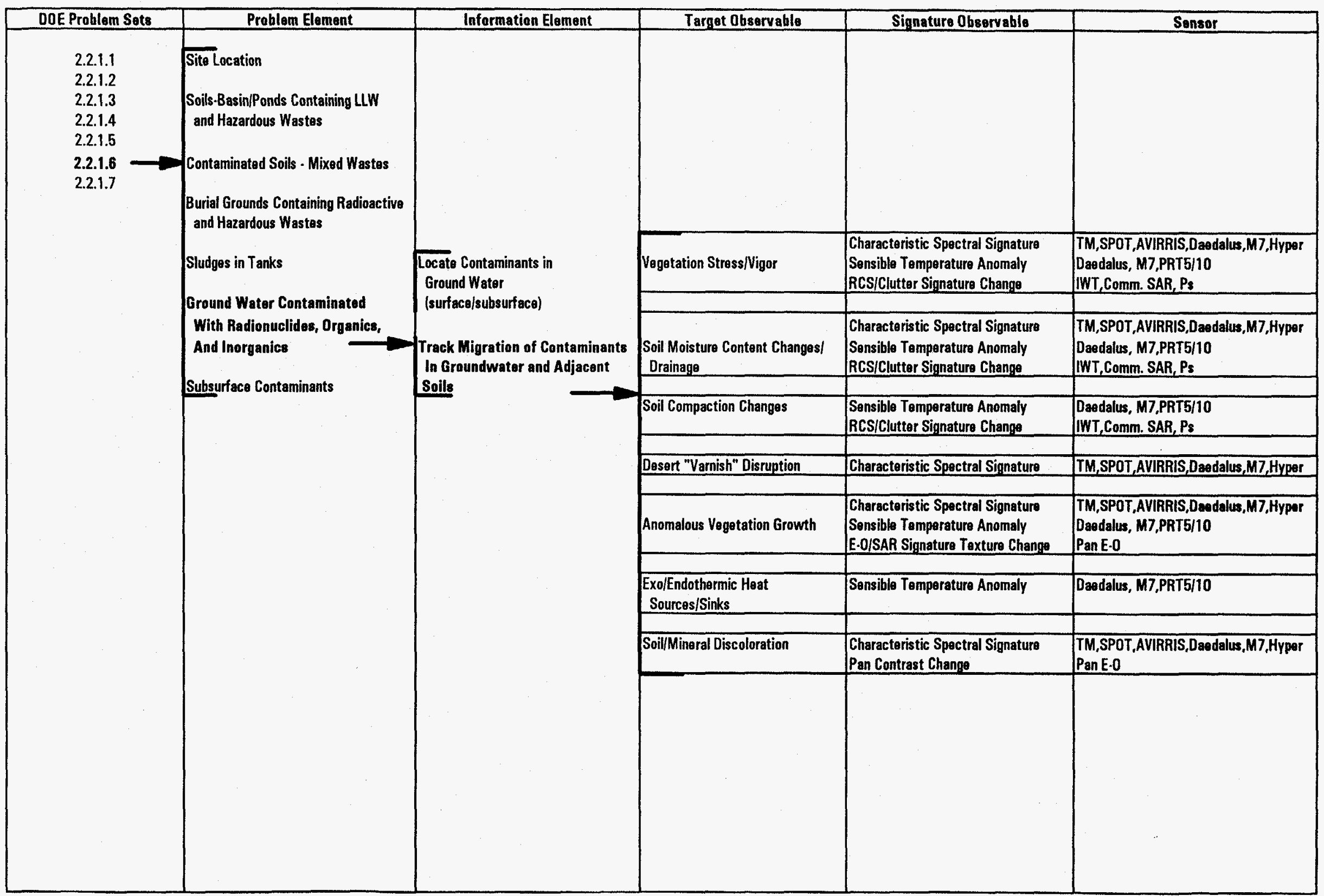


A.9.7.1 Target Observables, Signature Observables, and potential Sensors Associated with Information Elements Derived from "Subsurface Contaminants" Problem Element

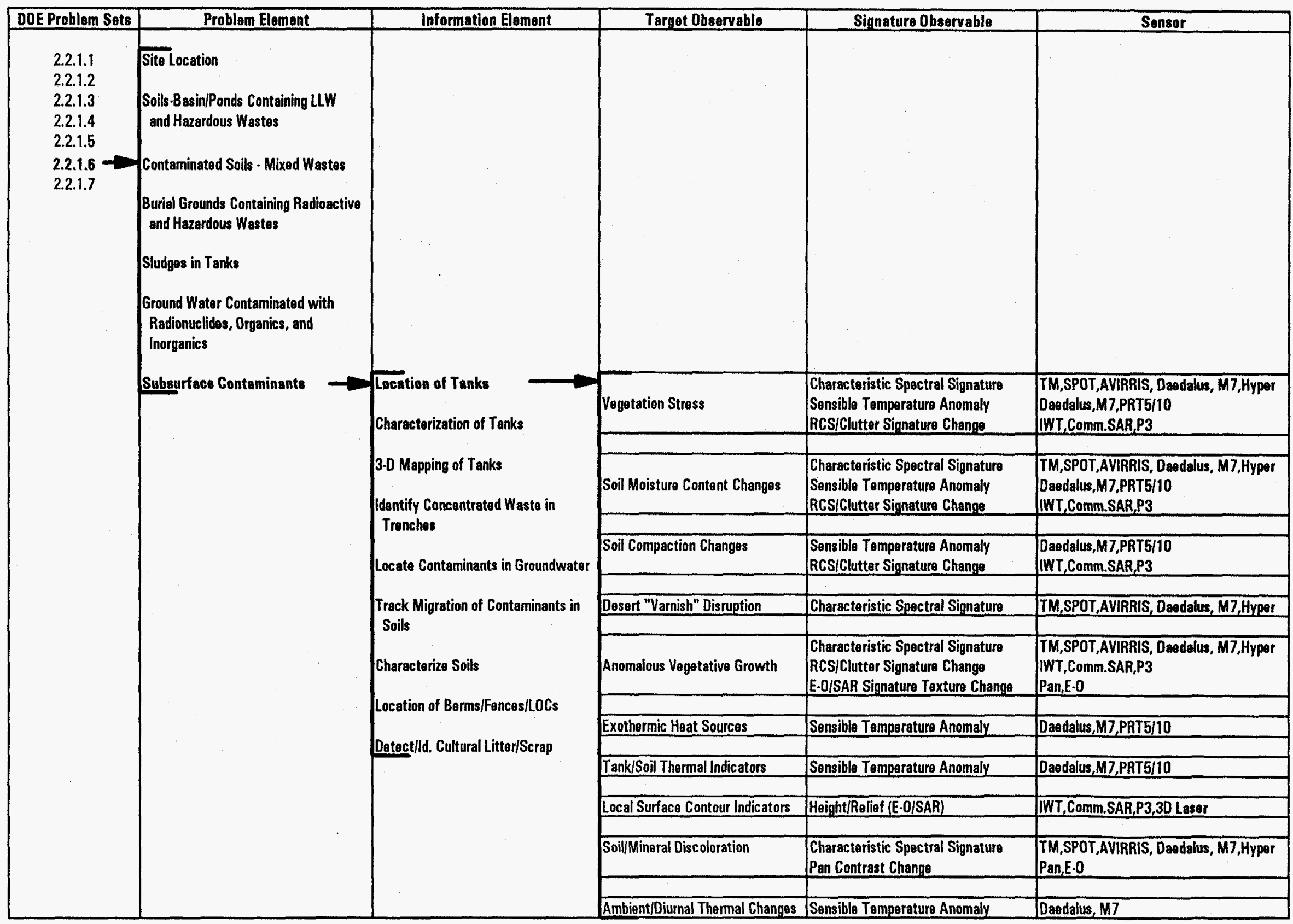


A.9.7.2 Target Observables, Signature Observables, and potential Sensors Associated with Information Elements Derived from "Subsurface Contaminants" Problem Element

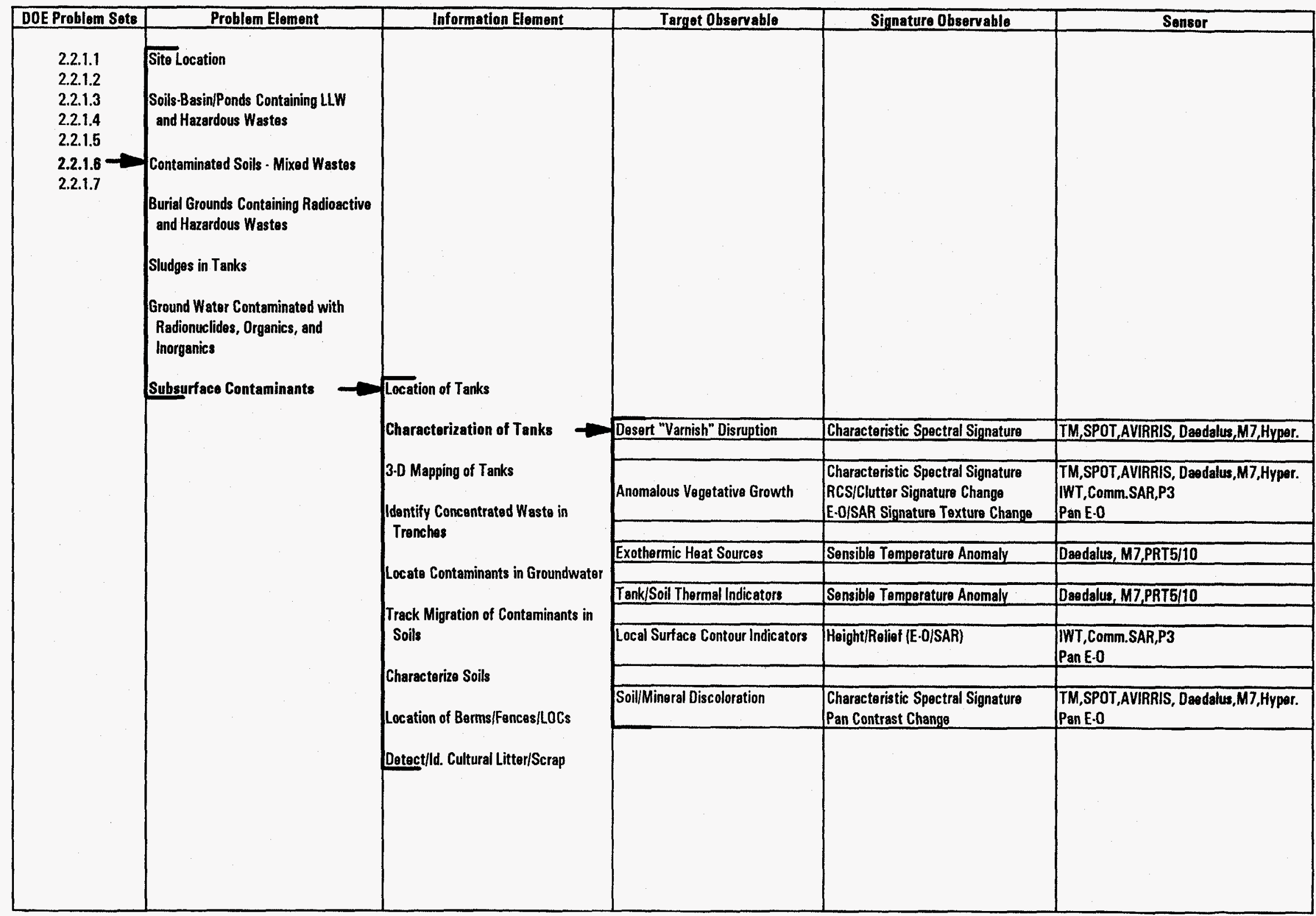




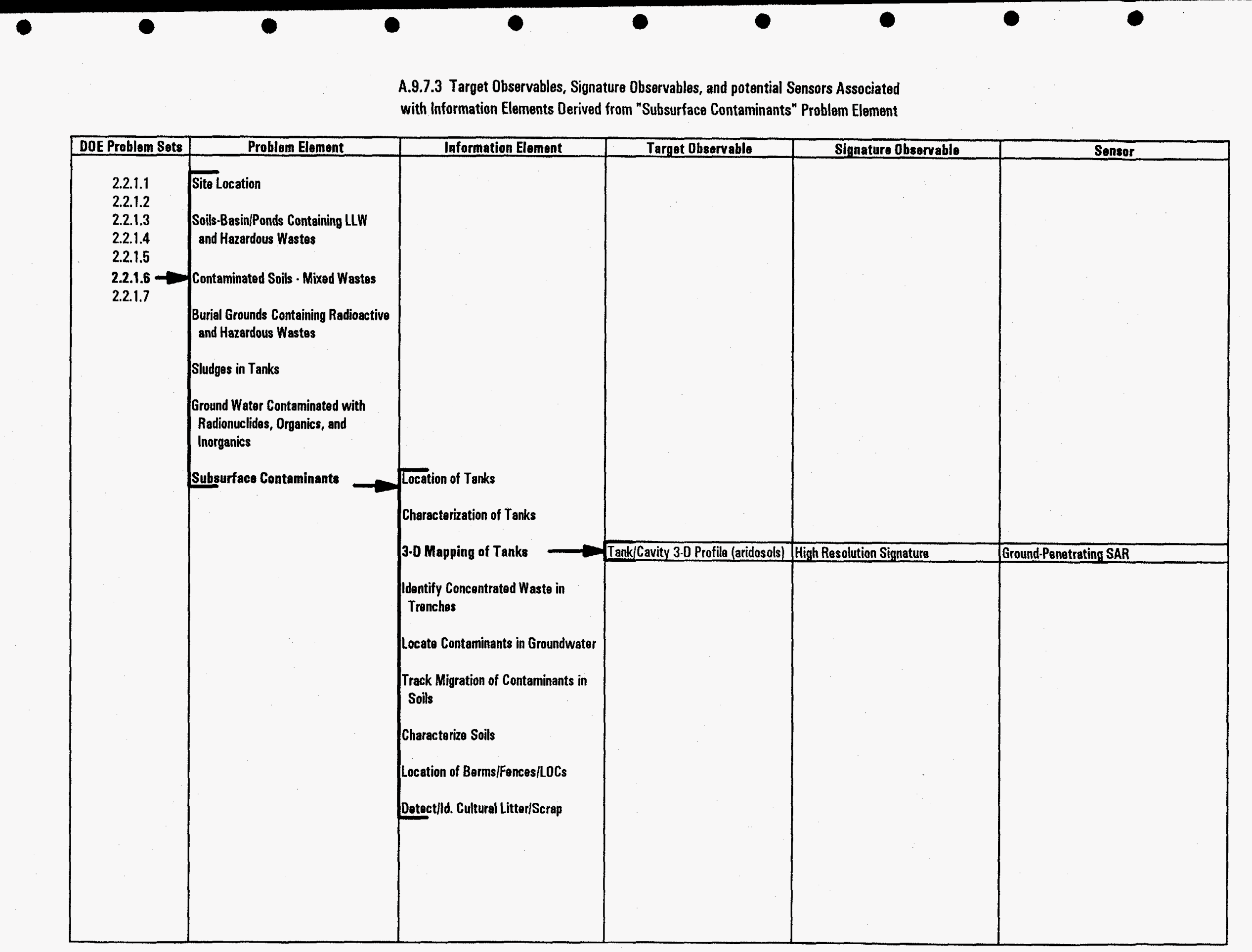


9.7.4 Target Observables, Signature Observables, and potential Sensors Associater with Information Elements Derived from "Subsurface Contaminants" Problem Element

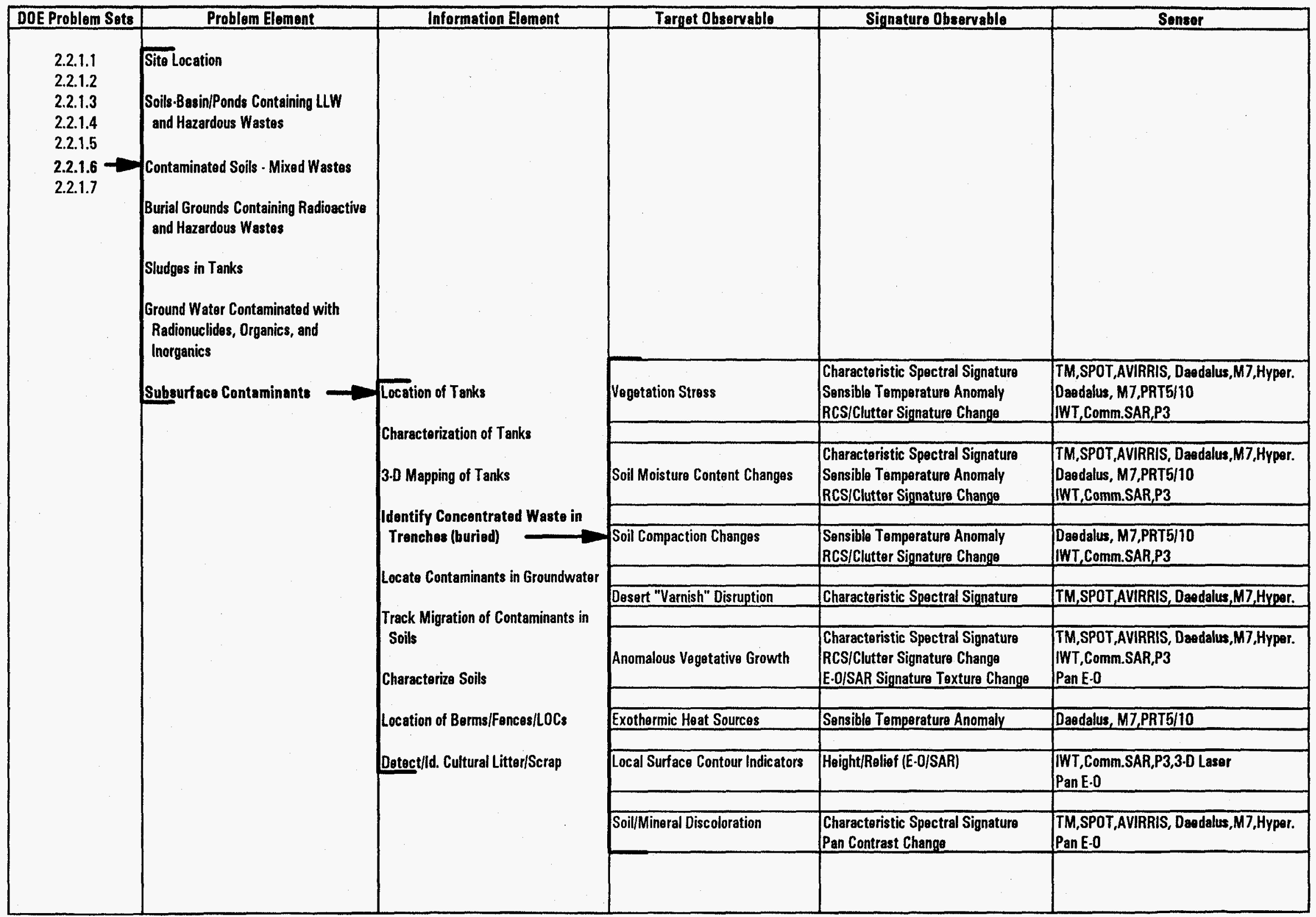


A.9.7.5 Target Observables, Signature Observables, and potential Sensors Associated with Information Elements Derived from "Subsurface Contaminants" Problem Elements

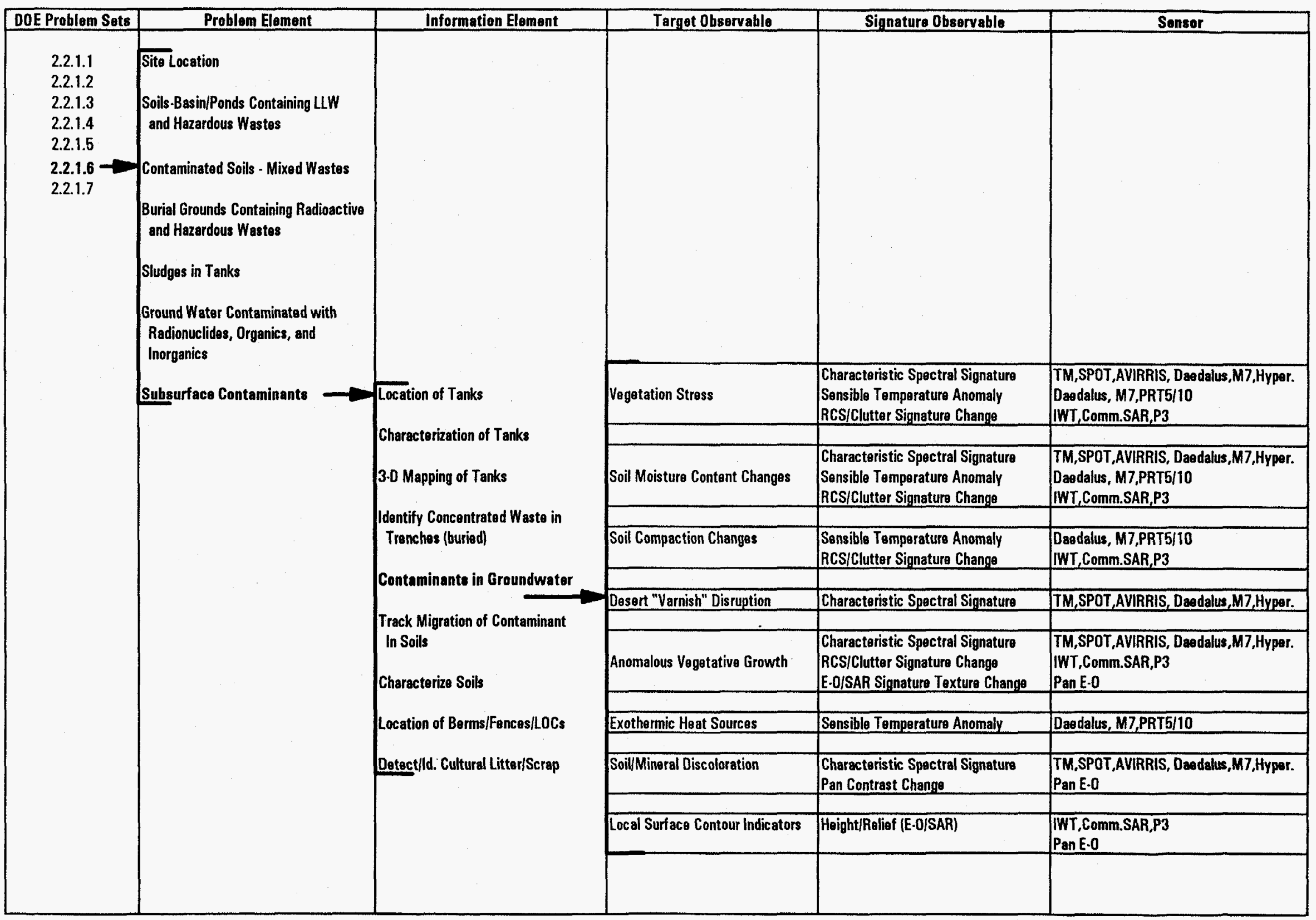


A.9.7.6 Target Observables, Signature Observables, and potential Sensors Associated

with Information Elements Derived from "Subsurface Contaminants" Problem Element

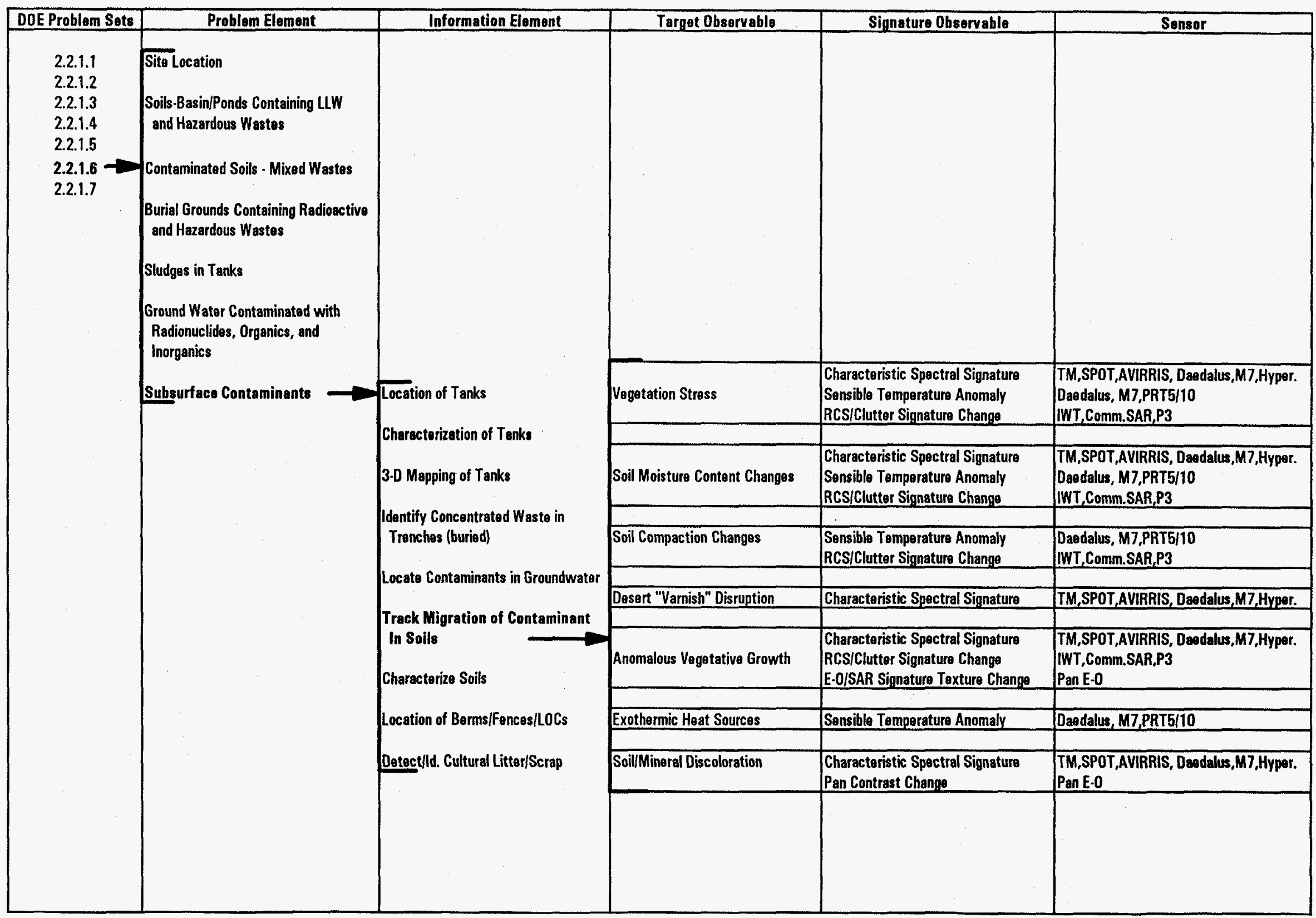


A.9.7.7 Target Observables, Signature Observables, and potential Sensors Associated with Information Elements Derived from "Subsurface Contaminants" Problem Element

\begin{tabular}{|c|c|c|c|c|c|}
\hline DOE Problem Sots & Problem Element & Information Element & Target Observable & Signature Observable & Sensor \\
\hline $\begin{array}{l}2.2 .1 .1 \\
2.2 .1 .2 \\
2.2 .1 .3 \\
2.2 .1 .4 \\
2.2 .1 .5 \\
2.2 .1 .6 \\
2.2 .1 .7\end{array}-$ & $\begin{array}{l}\text { Sita Location } \\
\text { Soils-Basin/Ponds Containing LLW } \\
\text { and Hazardous Wastes } \\
\text { Contaminated Soils - Mixed Wastos } \\
\text { Burial Grounds Containing Radioactive } \\
\text { and Hazardous Wastes } \\
\text { Sludges in Tanks } \\
\text { Ground Water Contaminated with } \\
\text { Radionuclides, Organics, and } \\
\text { Inorganics }\end{array}$ & 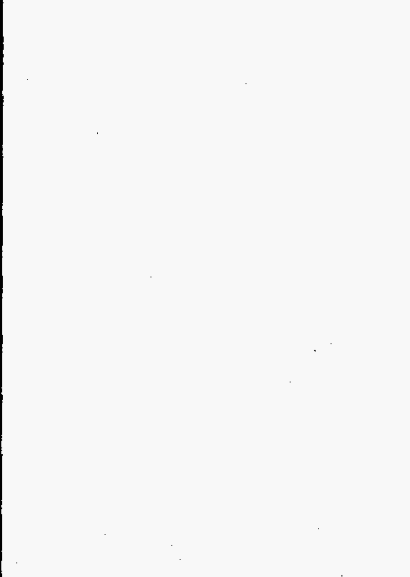 & & • & \\
\hline & Subsurface Contaminants & Location of Tanks & Vegatation Stress & $\begin{array}{l}\text { Characteristic Spectral Signature } \\
\text { Sensible Temperature Anomaly } \\
\text { RCS/Clutter Signature Change }\end{array}$ & $\begin{array}{l}\text { TM,SPOT,AVIRRIS, Daedalus,M7,Hyper. } \\
\text { Daedalus, M7,PRT5/10 } \\
\text { IWT,Comm.SAR,P3 }\end{array}$ \\
\hline & & $\begin{array}{l}\text { Characterization of Tanks } \\
\text { 3.D Mapping of Tanks }\end{array}$ & Soil Moisture Content Changes & $\begin{array}{l}\text { Characteristic Spectral Signature } \\
\text { Sensible Temperature Anomaly } \\
\text { RCS/Ciutter Signature Change }\end{array}$ & $\begin{array}{l}\text { TM,SPOT,AVIRRIS, Daodalus, M7, Hyper. } \\
\text { Daedalus, M7,PRT5/10 } \\
\text { IWT,Comm.SAR,P3 }\end{array}$ \\
\hline & & $\begin{array}{l}\text { Identify Concentrated Waste in } \\
\text { Trenches (buried) }\end{array}$ & Soil Compaction Changes & $\begin{array}{l}\text { Sensible Temperature Anomaly } \\
\text { RCS/Clutter Signature Change } \\
\end{array}$ & $\begin{array}{l} \\
\text { Daedalus, M7,PRT5/10 } \\
\text { IWT,Comm.SAR,P3 }\end{array}$ \\
\hline & & Locate Contaminants in Groundwater & Desert "Varnish" Disruption & Characteristic Spectral Signature & TM,SPOT,AVIRRIS, Dagdalus, M7,Hyper. \\
\hline & & $\begin{array}{l}\text { Track Migration of Contaminant } \\
\text { In Soils } \\
\text { Characterize Soils }\end{array}$ & Anomalous Vegatative Growth & $\begin{array}{l}\text { Characteristic Spectral Signature } \\
\text { RCS/Clutter Signature Changs } \\
\text { E.O/SAR Signature Texture Change }\end{array}$ & $\begin{array}{l}\text { TM,SPOT,AVIRRIS, Daedalus, M7,Hyper. } \\
\text { IWT,Comm.SAR,P3 } \\
\text { Pan E-0 }\end{array}$ \\
\hline & & Location of Berms/Fences/LOCs & Exothermic Heat Sources & Sensible Temperature Anomaly & Daedalus, M7,PRT5/10 \\
\hline & & Detect/ld. Cultural Litter/Scrap & Soil/Mineral Discoloration & $\begin{array}{l}\text { Characteristic Spectral Signature } \\
\text { Pan Contrast Change }\end{array}$ & $\begin{array}{l}\text { TM,SPOT,AVIRRIS, Daedalus,M7,Hyper. } \\
\text { Pan E-0 }\end{array}$ \\
\hline & & & Principle Chemical Constituents & Characteristic Spectral Signature & High Resolution Spectroradiometer, Hyper \\
\hline & & & & & \\
\hline
\end{tabular}


A.9.7.8 Target Observables, Signature Observables, and potential Sensors Associated with Information Elements Derived from "Subsurface Contaminants" Problem Element

\begin{tabular}{|c|c|c|c|c|c|}
\hline DOE Problem Sots & Problem Element & Information Element & Target Observable & Signature Ohservahlo & Sensar \\
\hline $\begin{array}{l}2.2 .1 .1 \\
2.2 .1 .2 \\
2.2 .1 .3 \\
2.2 .1 .4 \\
2.2 .1 .5 \\
2.2 .1 .6 \\
2.2 .1 .7\end{array}$ & $\begin{array}{l}\text { Sito Location } \\
\text { Soils-Basin/Ponds Containing LLW } \\
\text { and Hazardous Wastes } \\
\text { Contaminatod Soils - Mixed Wastes } \\
\text { Burial Grounds Containing Radioactivo } \\
\text { and Hazardous Wastes } \\
\text { Sludges in Tanks } \\
\text { Ground Wator Contaminatod with } \\
\text { Radionuclides, Organics, and } \\
\text { Inorganics }\end{array}$ & : & & & 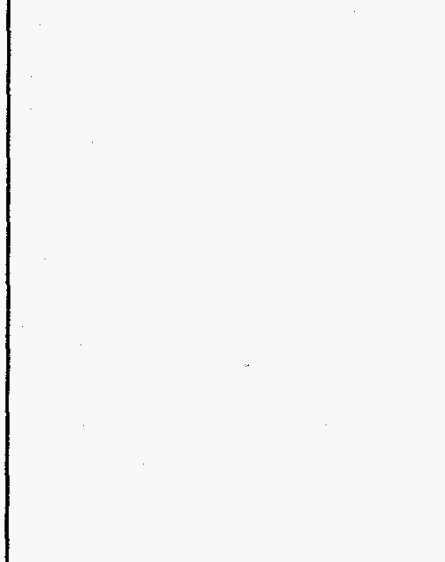 \\
\hline & Subsurface Contaminants & Location of Tanks & Vegetation Stress/Vigor & $\begin{array}{l}\text { Characteristic Spectral Signature } \\
\text { Sensible Temperature Anomaly } \\
\text { RCS/Clutter Signature Change }\end{array}$ & $\begin{array}{l}\text { TM,SPOT,AVIRRIS, Dagdalus,M7,Hypor. } \\
\text { Daedalus, M7,PRT5/10 } \\
\text { IWT,Cornm.SAR,P3 }\end{array}$ \\
\hline & & $\begin{array}{l}\text { Charactorization of Tanks } \\
\text { 3-0 Mapping of Tanks }\end{array}$ & Soil Moisture Content Changes & $\begin{array}{l}\text { Characteristic Spectral Signature } \\
\text { Sensible Temperature Anomaly } \\
\text { RCS/Clutter Signature Change } \\
\text { E-O/SAR Signature Texture Change } \\
\end{array}$ & $\begin{array}{l}\text { TM,SPOT,AVIRRIS, Daedalus, M7,Hypar. } \\
\text { Daadalus, M7,PRT5/10 } \\
\text { IWT,Comm.SAR,P3 } \\
\text { PanE.0 }\end{array}$ \\
\hline & & $\begin{array}{l}\text { Identify Concentrated Waste in } \\
\text { Trenches (buried) }\end{array}$ & Soil Compaction Changes & \begin{tabular}{|l|} 
Sensible Temperature Anomaly \\
RCS/Clutter Signature Change \\
E.O/SAR Signature Texture Change \\
\end{tabular} & $\begin{array}{l}\text { Daedalus, M7,PRT5/10 } \\
\text { IWT,Comm.SAR,P3 } \\
\text { PanE-0 }\end{array}$ \\
\hline & & & Desart "Varnish" Disruption & Characteristic Spectral Signature & TM,SPOT,AVIRRIS, Daedalus,M7,Hyper. \\
\hline & & $\begin{array}{l}\text { Track Migration of Contaminant } \\
\text { In Soils } \\
\text { Characterize Soils }\end{array}$ & Anomalous Vegetative Growth & $\begin{array}{l}\text { Characteristic Spectral Signature } \\
\text { RCS/Clutter Signature Change } \\
\text { E-O/SAR Signature Texture Change } \\
\end{array}$ & $\begin{array}{l}\text { TM,SPOT,AVIRRIS, Daodalus, M7,Hyper. } \\
\text { IWT,Comm.SAR,P3 } \\
\text { Pan E-0 }\end{array}$ \\
\hline & & Location of Berms/Fonces/LOCs & Ambient/Diurnal Thermal Change & Sensible Temperature Anomaly & Daodalus, M7,PRT5/10 \\
\hline & & Detect/ld. Cultural Litter/Scrap & Soil/Mineral Discoloration & $\begin{array}{l}\text { Characteristic Spectral Signature } \\
\text { Pan Contrast Change }\end{array}$ & $\begin{array}{l}\text { TM,SPOT,AVIRRIS, Daodalus,M7,Hyper. } \\
\text { Pan E-O }\end{array}$ \\
\hline & & & Fances/Posts/Footings & Point/Extanded Signatures & IWT,Comm,SAR,P3 \\
\hline
\end{tabular}


A.9.7.9 Target Observables, Signature Observables, and potential Sensors Associated with Information Elements Derived from "Subsurface Contaminants" Problem Elements

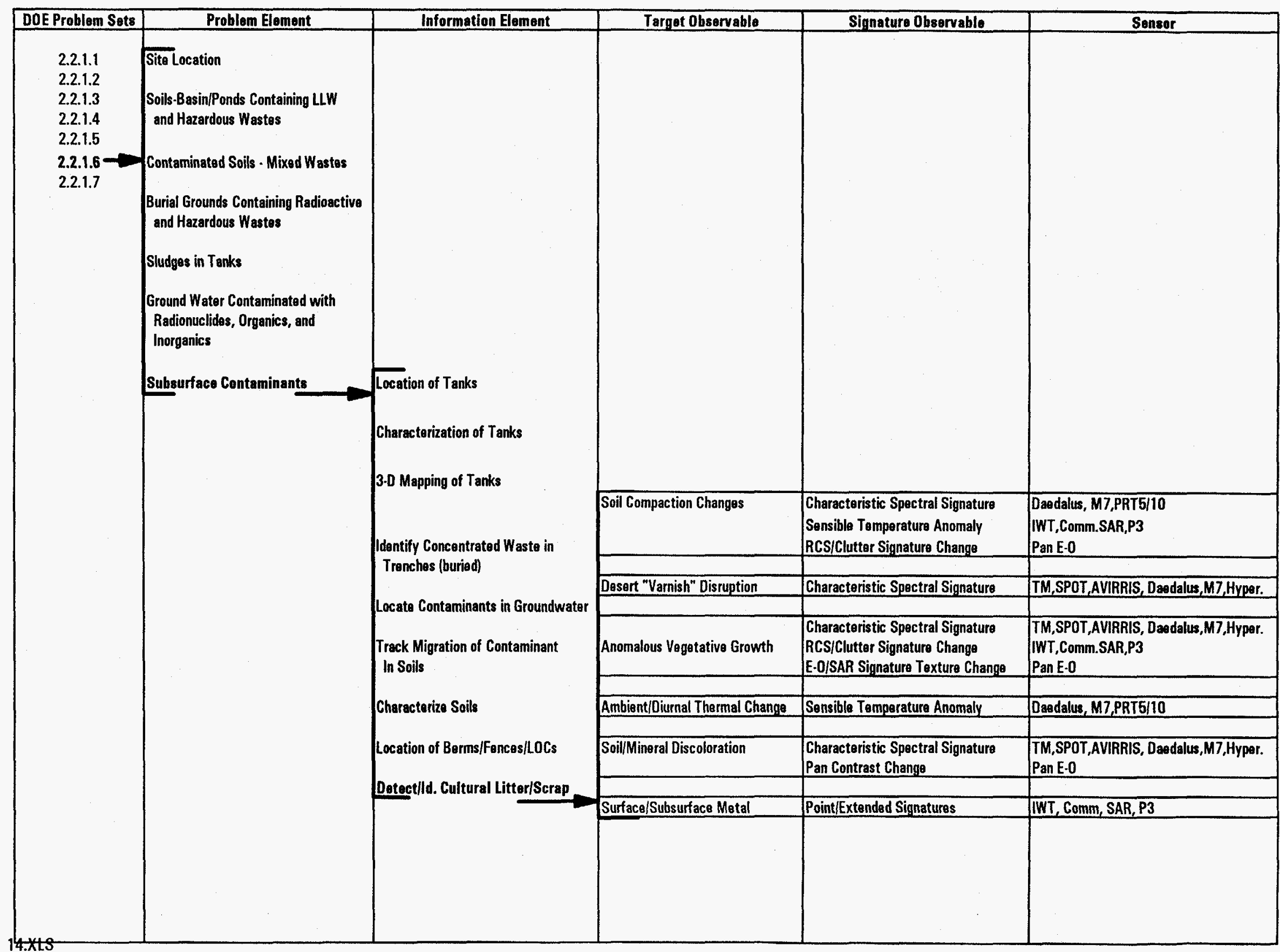

